\title{
The Moral Standing of Animals: Towards a Psychology of Speciesism
}

\author{
Journal of Personality and Social Psychology \\ Lucius Caviola, Jim A.C. Everett, and Nadira S. Faber \\ University of Oxford
}

\begin{abstract}
We introduce and investigate the philosophical concept of 'speciesism' - the assignment of different moral worth based on species membership - as a psychological construct. In five studies, using both general population samples online and student samples, we show that speciesism is a measurable, stable construct with high interpersonal differences, that goes along with a cluster of other forms of prejudice, and is able to predict real-world decisionmaking and behavior. In Study 1 we present the development and empirical validation of a theoretically driven Speciesism Scale, which captures individual differences in speciesist attitudes. In Study 2, we show high test-retest reliability of the scale over a period of four weeks, suggesting that speciesism is stable over time. In Study 3, we present positive correlations between speciesism and prejudicial attitudes such as racism, sexism, homophobia, along with ideological constructs associated with prejudice such as social dominance orientation, system justification, and right-wing authoritarianism. These results suggest that similar mechanisms might underlie both speciesism and other well-researched forms of prejudice. Finally, in Studies 4 and 5, we demonstrate that speciesism is able to predict prosociality towards animals (both in the context of charitable donations and time investment) and behavioral food choices above and beyond existing related constructs. Importantly, our studies show that people morally value individuals of certain species less than others even when beliefs about intelligence and sentience are accounted for. We conclude by discussing the implications of a psychological study of speciesism for the psychology of human-animal relationships.
\end{abstract}

Keywords: speciesism, prejudice, prosocial behavior, human-animal relations, helping

(C) 2018, American Psychological Association. This paper is not the copy of record and may not exactly replicate the final, authoritative version of the article. Please do not copy or cite without authors permission. The final article will be available, upon publication, via its DOI: 10.1037/pspp0000182

Please note that this the authors' copy of the published manuscript, provided for the purpose of disseminating academic research openly. For referencing purposes, please see the final published manuscript for the correct 


\section{The Moral Standing of Animals: Towards a Psychology of Speciesism}

Human relationships with non-human animals are complex. Some animals are treasured as pets, receive our love and devotion and are provided with a diet and quality of health care better even than some humans in the developing world. Other animals, in contrast, are factory farmed and slaughtered so that their bodies can provide the meat we share with our pets. Yet other animals are regarded as experimental subjects, sources of entertainment, or industrial equipment. Any observer who had not been socialized to view this as normal would likely be struck by this inconsistency of moral worth attributed to animals in human societies. In this paper, we attempt to understand this paradoxical treatment by importing the philosophical concept of speciesism into a social-psychological examination of human-animal relationships.

\section{The Philosophy of Speciesism}

Philosophers have long noted the inconsistency in our regard for animals, but it is only in recent decades that the systematic consideration of human-animal relations has really flourished and entered the public domain. Our relationships with animals have been called "speciesist" - a term introduced and popularized in the 1970s and specifically intended to draw a parallel with other forms of unjustified discrimination, such as racism and sexism (Horta, 2010; Ryder, 2006, Singer, 1975; 1979; Singer \& Mason, 2007). Speciesism, in the philosophical literature, refers to the assignment of different inherent moral status based solely on an individual's species membership. As implicit in the definition of speciesism and its very name, speciesism can be understood in both a descriptive and a normative sense.
Descriptively, speciesism is a concept that explains how people behave; namely that they do, as a matter of fact, assign moral worth to individuals on the basis of species membership, such that people can therefore be accurately described as having speciesist attitudes. Normatively, much work on speciesism is rooted in the claim that people should not assign different moral values to individuals based solely on their species membership, with analogies made with treating people differently solely based upon their race (racism) or gender (sexism). This paper is concerned with speciesism as a psychological phenomenon and, therefore, in a descriptive sense.

Speciesism manifests itself in the nearuniversal belief that humans are intrinsically more valuable than individuals of other species. It also manifests itself in the belief that differential treatment of species that have comparable mental and emotional capabilities, such as pigs and dogs, is morally justifiable. These manifestations of speciesism are ubiquitous, underpinning practices such as the mass factory farming of animals for food, the use of animals for human entertainment in circuses, and legal systems that view animals as property and deny them basic rights such as the right to bodily integrity. For example, we treat dogs with special moral status while simultaneously factory farming and eating pigs - despite the fact that dogs and pigs have similar mental and emotional capabilities (Mendl, Held, \& Byrne, 2010). Such manifestations of speciesism are, descriptively, familiar to all, even if one might deny there is anything, normatively, wrong with this. Speciesism-like racism and sexism-is observed throughout history and across cultures. Just like ethnic prejudice is observed in all societies but is directed against different groups based on local traditions and history, speciesism appears evident across cultures but is expressed differently across the world (see Amiot \& 
Bastian, 2015). Consider dogs and cats: in China they are considered food and thus akin to other animals like pigs, but in Western societies they are seen as 'one of the family' and thus have a much higher status than pigs (Simoons, 1990). Or consider cows: routine fare on the dinner plate in many Western countries, but forbidden from being eaten and revered as sacred animals in Hindu societies. These culturally determined manifestations of speciesism occur not just across cultures but also across time. Horses were once routinely consumed in Western countries for centuries, but now horsemeat consumption has substantially declined and the perceived moral status of horses has increased (Gade, 1976).

At this point, one might ask whether it is really speciesism that best explains why we treat people and animals differently based on their species (for philosophical criticism of speciesism as a concept see Diamond, 1978; Kagan, 2016, Williams, 2009). Just as it has been argued in history that unequal treatment of races is morally justified because members of different races (supposedly) differ in their intelligence or physical capabilities, might it not be species membership per se that results in differential treatment, but rather other traits that happen to correlate with species membership? Three of the most common objections to the utility of the speciesism concept, raised by philosophers and laypeople alike, are that rather than reflecting a speciesist bias, humans devalue animals because: a) animals are less cognitively able than humans; b) animals, unlike humans, cannot be moral agents (i.e. they cannot reciprocate in moral interactions and cannot be held morally or legally responsible for their actions); or c) animals are less sentient (i.e. able to feel and experience things such as suffering) than humans.

Were any of the above the true cause of human treatment of animals, speciesism would be a redundant concept.
And yet, careful analysis suggests that this is not the case. When each of the above reasons is investigated more fully, they are shown to be incomplete explanations (see, for example, Horta, 2010).

a) First, the argument from cognitive abilities (i.e. that humans devalue animals because they are less cognitively able than humans) fails to account for why people place different moral value on different animals that have similar cognitive abilities. Pigs, for example, have higher cognitive abilities than dogs, and even pass a weak version of the mirror test, indicating some level of selfawareness (Broom, Sena \& Moynihan, 2009). It cannot, therefore, simply be cognitive abilities that determine treatment, because otherwise pigs would be treated as equal, and maybe even superior, to dogs. Of course, some people might morally value pigs less than dogs because they incorrectly assume that pigs are less intelligent than they actually are, which might be driven by motivated reasoning (e.g. Bastian et al., 2012). But such incorrect assumptions and/or motivated reasoning cannot explain clear cases of people valuing certain individuals less despite being fully aware that they are equally or more intelligent than others (for example, chimpanzees vs. severely mentally disabled humans, see point $b$ ).

b) Second, the arguments from both cognitive abilities and moral agency (i.e. humans devalue animals because animals, unlike humans, cannot be moral agents) are countered with the example of severely mentally disabled humans. Humans grant equal moral status to severely mentally disabled humans and healthy 
individuals despite their lack of cognitive and reciprocal abilitiesthey may even grant such individuals enhanced moral status in light of their vulnerability. Moreover, it seems that most people would place less moral value on a chimpanzee than on a human with very severe mental disabilities even in cases where they know that the chimpanzee has higher cognitive abilities than said human. Neither cognitive abilities nor the potential for reciprocal morality, then, seem to accurately account for the way we treat members of different species, because otherwise we should afford greater weight to the treatment of intelligent animals over severely disabled humans.

c) Third, the argument from sentience (i.e. animals do not feel and experience things such as suffering) fails because empirical data has shown that many animals - and in particular vertebrate, like pigs, dogs, and cows - are capable of suffering to an extent analogous to humans (Low et al., 2012). It is possible, however, that people systematically underappreciate the level of sentience in many animals. Moreover, even in the absence of this overwhelming scientific data, we can observe that people do not typically doubt the sentience of, for example, human infants despite the fact that the behavior of infants offers weaker evidence for sentience than the behavior of, for example, an average adult chimpanzee.

Given these arguments, the standard objections to the utility of the philosophical concept of speciesism are unconvincing. People do seem to assign worth to different species solely on species membership. And even if one disagrees on just how unconvincing these criticisms are, it seems clear that they are not strong enough to halt discussion of speciesism in its tracks. From a philosophical perspective, the paradoxical treatment of animals can be usefully, and informatively, described as speciesist. And indeed this is where speciesism has most often been used-in philosophy. But could speciesism also be a useful psychological construct, shedding deeper light on the way that humans think about animals? We argue that it can.

\section{The Psychology of Speciesism}

In this paper, we present speciesism as a psychological construct, suitable for psychological investigation. Specifically, we are interested in the empirical truth of the psychological claims implicit in the philosophical discussion of speciesism: first, the primary claim that people assign moral worth to individuals on the basis of species membership alone; and second, the claim that speciesism is a form of prejudice analogous to other prejudicial attitudes. Philosophers have debated these claims, but relatively little empirical work has been conducted to test whether these claims are, as a matter of fact, true. Do people, in actuality, assign moral worth to individuals on the basic of species membership; and are these speciesist attitudes connected to other prejudicial attitudes? By rigorously examining this, it becomes possible to bring the concept of speciesism into the study of intergroup relations and prejudice more generally, thus providing new insights and directions for research for both topics.

Our preliminary aim, upon which all later aims depend, was (Aim I) to develop a reliable and valid scale to measure speciesism as a psychological construct (Studies 1 and 2). Once this was achieved, we aimed to look at (Aim II) the extent to which speciesism can psychologically be 
considered a form of a prejudice (Study 3), by testing whether (Aim IIa) speciesism correlates with other forms of prejudice, and whether (Aim IIb) speciesism, like other forms of prejudice, is driven by socio-ideological factors such as social dominance orientation that maintain other forms of intergroup conflict. To the extent that speciesism is a form of prejudice it should be correlated with prototypical examples of prejudice and be driven by the same kind of processes that drive other prejudices. Moreover, we aimed to explore the relationship between speciesism with empathic concern and actively open-minded thinking (Aim IIc). Finally, we aimed to look at (Aim III) whether speciesism predicts behavior, such as the degree of help directed towards individuals of different species or the likelihood of choosing certain food products over others (Studies 4 and 5).

To what extent is it reasonable, on empirical grounds, to view speciesism as a form of prejudice? It is here that psychology has a real and important role to play. If it can be shown that speciesism is psychologically related to other forms of prejudice, the philosophical case for it can be strengthened. One typical definition of prejudice is that it refers to "any attitude, emotion, or behavior toward members of a group, which directly or indirectly implies some negativity or antipathy toward that group" (Brown, 2010, p. 7). Speciesism seems to fit that definition as it involves negative beliefs, emotions, and behavior directed towards others based on species membership. Most people believe that pigs matter less than dogs (attitude), feel disgust towards rats but love towards cats (emotion), and accordingly treat pigs and rats much worse than they treat dogs and cats (behavior). Moreover, in addition to fitting the definition of prejudice, we aim to show that speciesism shares properties and underlying psychological mechanisms with other phenomena referred to as prejudice.

\section{Previous Research}

As noted above, surprisingly little psychological research has focused on the discrimination against animals (for one of the first papers, see Plous, 1993). There are, however, some previous and more recent studies on human-animal relations, their underlying attitudes, mechanisms and resulting practices that suggest it is in fact useful to consider speciesism in terms of intergroup bias, prejudice, and discrimination.

\section{The Social Dominance Human-Animal Relations Model (SD-HARM)}

The first connection between speciesism and intergroup bias comes in the form of social dominance orientation (SDO: Pratto, Sidanius, Stallworth, \& Malle, 1994). People differ in how much they support or oppose group-based dominance and inequality amongst social groups, and this variance can be referred to as differences in social dominance orientation. Differences in SDO predict prejudicial attitudes towards a variety of human social groups, including ethnic minorities, housewives, people with mental health difficulties, and people who are obese or perceived as unattractive (e.g. Duckitt \& Sibley, 2007). Critically for a discussion of speciesism, SDO also relates to how people feel about inequality between humans and animals. Recent studies suggest that people who believe in the superiority of humans over animals also believe in the superiority of some humans over others (Costello \& Hodson, 2009; Dhont \& Hodson, 2014; Dhont, Hodson, Costello \& MacInnis, 2014). Accordingly, Dhohnt, Hodson and Leite (2016) have proposed the Social Dominance Human-Animal Relations Model (SD-HARM) whereby the same socio-ideological beliefs that legitimize hierarchies amongst human groups also seem to legitimize hierarchies of humans over animals. Such findings suggest that it would be fruitful to consider speciesism in terms of intergroup conflict, if both 
speciesism and other forms of prejudice depend on similar psychological beliefs.

\section{Dehumanization and the Interspecies Model of Prejudice (ISMP)}

The second connection between speciesism and intergroup conflict comes from work on dehumanization, and specifically research suggesting that intergroup dehumanization is linked with beliefs in the superiority of humans over animals. Dehumanization is the psychological process by which other people are seen as less "human" and therefore not worthy of full moral concern, and is a critical part of intergroup conflict (Haslam, 2006). The language of dehumanization, such as referring to black people as "apes", Jews as "rats" and women as "bitches", works to strip the victim of moral worth, as it is assumed that actual apes, rats, and dogs could not merit full moral consideration. Two distinct accounts have been proposed to explain the relationship between dehumanization and attitudes towards animals.

One the one hand, it has been suggested that just as some people dehumanize human out-groups by reducing attribution of mental states, they also de-mentalize animal out-groups. Specifically, the denial of animals' capability to suffer, known as dementalization, can reduce moral concern for animals (Bastian et al., 2012; Kozak, Marsh, \& Wegner, 2006). Indeed, research shows that a person's moral concern for animals is closely related to how much they believe animals can suffer (Waytz, Gray, Epley, \& Wegner, 2010).

On the other hand, according to the Interspecies Model of Prejudice (ISMP: Costello \& Hodson, 2014), belief in an insurmountable human-animal divide is the foundation for out-group dehumanization. That is, dehumanization is made possible by the moral gulf between human and animals: By likening out-group members to 'inferior' animals, people who endorse social dominance are able to remove their victims from the 'human' sphere of moral concern and place them in the 'animal' sphere where no moral consideration is necessary. The existence of the human-animal gulf therefore functions to facilitate prejudice and discrimination between groups of humans as well as between humans and animals. In support of this theory, it was demonstrated that when similarities between animals and humans are pointed out not only speciesism is reduced but also moral concern for marginalized human out-groups is increased (Bastian, Loughnan, Costello, \& Hodson, 2012).

\section{The Meat Paradox and Carnism}

A related emerging field of research has started to investigate the psychology surrounding practices of eating animals (Loughnan \& Bastian, 2014). Most people do not want to hurt animals, yet continue to eat meat. This widespread phenomenon has been referred to as the 'meat paradox' (Loughnan et al., 2010; Loughnan, Bastian, \& Haslam, 2014). Both active (motivated reasoning) and passive (e.g. social norms) dissonance avoidance can account for the meat paradox (Bastian \& Loughan, 2017).

A main driver of the meat paradox is de-mentalization (discussed above). People tend to de-mentalize animals they classify as food (e.g. Bastian et al., 2012) and judge animals that are categorized as food (e.g. pigs, cows, chickens) as having lower capability to suffer than animals that are typically not categorized as food (e.g. cats, dogs, horses; Bilewicz, Michalak, \& Kamińska, 2016; Bratanova, Loughnan, \& Bastian, 2011). Moreover, people are more likely to de-mentalize animals if they have recently eaten meat (Loughnan, Haslam, \& Bastian, 2010) or if they anticipate eating meat soon (Bastian et al., 2012; Bastian \& Loughnan, 2016).

It has been argued that meat consumption is legitimized by a set of ideological beliefs referred to as 'carnism' (Joy, 2011; Monteiro, Pfeiler, Patterson \& 
Milburn, 2017). Eating meat, for example, is justified on the basis of it being natural, normal, necessary, and nice ("The $4 \mathrm{Ns}^{\text {"; }}$ Piazza et al., 2015). Furthermore, carnism shows in the justification of killing animals for food purposes (Monteiro et al., 2017). Conceptually, carnism is a specific subset of speciesist beliefs and practices, namely those related to the categorization of certain animals as food. Psychologically, we would expect carnism and speciesism to be to some extent distinct due to the fact that many people care about animals in general while at the same time defending meat consumption and its practices (i.e. meat paradox). Overall, however, it seems likely that the two are not just conceptually but also psychologically strongly linked.

\section{Measuring Speciesism}

To study speciesism, we need a convenient way of measuring speciesist attitudes. There are currently two established scales that attempt to capture general attitudes towards animals: Herzog, Betchart, and Pittman's (1991) Animal Attitude Scale and Wuensch, Jenkins, and Poteat's (2002) Animal Rights Scale. Both scales capture important aspects of people's attitudes towards animals. For many reasons, however, we argue that a new scale is needed in order to examine the psychology of speciesism specifically with sufficient precision. Dhont et al. $(2014 ; 2016)$ and Piazza et al. (2015) have also recognized the need for a new way to measure speciesism, and to this end developed ad hoc measurement instruments to help elucidate how humans think about animals. However, while these instruments have been used to good effect to advance our understanding of human-animal relationships, they suffer from theoretical limitations and were produced without statistical validation and established scale development procedures. A comprehensive validated measuring tool for speciesism therefore remains unavailable in the existing literature, for multiple reasons.

First, existing scales do not explicitly capture speciesism, as it is properly defined: Attributing moral status to an individual solely on the basis of their species. Instead, existing scales capture related, yet distinct, concepts such as general attitudes towards animals or views on animal rights.

Second, some items in existing scales confound empirical and normative issues. Consider the following item by Wuensch et al. (2002): "Most cosmetics research done on animals is unnecessary and invalid". This item is limited as it confounds the normative belief that animals should not be subjected to suffering with the empirical belief in the efficacy of scientific testing. There is no way to accurately respond to the item if, for example, you believe the research is scientifically valid but morally abhorrent, or if you believe the research is morally acceptable but scientifically useless. Or consider another item on the scale, which reads: "There are plenty of viable alternatives to the use of animals in biomedical and behavioral research" (Wuensch et al., 2002). Again, this item is flawed as it relates to an empirical fact, not a belief about the moral standing of animals. A coherent anti-speciesist could believe that there are few viable alternatives to the use of animals in research while maintaining testing on animals is morally wrong.

Third, a common difficulty in capturing speciesism is that people who endorse anti-speciesism can come to different conclusions about certain practices depending on the philosophical position they hold, such as consequentialism and deontology. Consequentialism, including utilitarianism, is the moral view that the rightness of an action depends only on its consequences (Bentham, 1789/1961; Mill, 1861). Deontology is the moral view that certain actions are forbidden irrespective 
of the consequences (Kant, 1785/1964). A consequentialist anti-speciesist might, for example, agree to harm animals (or humans) if this were to result in better overall outcome for all sentient beings (Kahane et al., 2015). A deontological antispeciesist, however, would refuse to harm animals (or humans) even if the outcome would be better for everyone. Given this divergence, unless carefully devised, items that, for example, assess people's attitudes on using animals for medical testing can be unhelpful (e.g. some items by Herzog et al., 1991). This is because they might distinguish between a consequentialist anti-speciesist (who may endorse research using animals if it results in the development of a drug that saves many lives in the long run), and a deontological anti-speciesist (who may reject research using animals because it violates a general rule of not harming others). Such a distinction, however, is a factor that should not be captured by a speciesism scale as, ultimately, the scale must be able to identify speciesism without being confounded by unrelated specifics of the underlying moral position a person may hold.

\section{Requirements for a Speciesism Scale}

In order to ensure that our scale captures the precise philosophical meaning of speciesism, we outlined the following requirements to be met:

First, the initial set of items (subjected to exploratory factor analysis) should capture speciesism both exclusively and exhaustively. We assume that speciesism will manifest itself both in general beliefs about the moral inferiority of certain species and in the endorsement of concrete practices involving the use of animals. All major manifestations of speciesism must be covered and core manifestations of speciesism must receive appropriate representation, such as the use of animals for entertainment, food, and medical experiments.
To capture all relevant manifestations of speciesism the item pool should consist of both abstract-general and concreteempirical items. There are benefits and drawbacks to including concrete items. On the one hand, benefits of concrete items include the fact that people's attitudes are likely to be inconsistent and limited by self-serving biases, and concrete items can expose this inconsistency. For example, people might agree with an abstract item such as "species membership is not a morally relevant criterion", but disagree with a concrete item such as "animals should not be hunted for sport". Another advantage of concrete items is that they may be easier for laypeople to understand and respond to. As this scale is primarily for use by laypeople and not philosophers, ease of comprehension is an important factor. On the other hand, disadvantages of concrete items include the fact that they inevitably create empirical confounders. Take a person's views on animals performing in the circus, for example. To some extent, the issue poses the empirical question of how far circus animals suffer. People might have different experiences of circuses, which might cause them to have different views on the level of suffering circuses cause for animals. These beliefs about circus conditions might be entirely independent of their moral values. Given these arguments about concrete items, we aimed to strike an appropriate balance between philosophically rigorous items and concrete items in the final scale.

Second, items should avoid normative confounders. In particular, it is important that items do not prompt different responses from deontological and consequentialist anti-speciesists. As we have explored above, there is the potential for consequentialist and deontological anti-speciesists to be divided on a number of issues related to the treatment or rights of animals. Therefore, when we referred to an 
empirical situation in our items, we ensured the situation was such that most consequentialist and deontological (anti-) speciesists would reach the same conclusion.

\section{Study 1. Scale Development}

In Study 1 we began our process of developing the Speciesism Scale (Aim I) by formulating and testing a pool of theoretically-validated items to measure speciesism.

\section{Method}

\section{Item Selection}

To formulate a list of items, we used a combination of partially modified versions of items from existing scales (Herzog et al. 1991; Wuensch et al. 2002) and entirely new items. We then sent these proposed items to renowned experts from a number of disciplines, including the philosophers Peter Singer and Oscar Horta, and the legal scholar Steven Wise'. After incorporating feedback from these experts and excluding items that did not meet our criteria, we were left with a 27 item pool (see Table 1). In line with our prerequisites for the scale, these items included both concrete (e.g. "It is morally acceptable for cattle and pigs to be raised for human consumption") and abstract items (e.g. "Some beings are morally more important than others just because they belong to a certain species."); and items tapping both the belief in the superiority of humans over animals ("Morally, animals always count for less than humans") and the superiority of certain animals over other animals ("Pigs should be taken care of by humans just like dogs are": reverse-scored).

\section{Ethics Statement}

Of course, while we sought feedback from these experts, we are fully responsible for these items should any criticism occur.
For all studies in this paper, our institution's ethical guidelines were followed and the research was approved through University of Oxford's Central University Research Ethics Committee, with the reference number MSD-IDRECC1-2014-133.

\section{Participants and Procedure}

1,122 US American participants took part in the study online via Amazon Mechanical Turk (MTurk), and received a payment of $\$ 0.50$ for their participation.. Five participants were excluded for not completing the study, and nine because they failed a simple attention check embedded in the survey where people were asked to select a certain scale point to confirm they were paying attention. This left a final sample of 1,108 participants (457 female; $M_{a g}=33, S D=$ 11.56), representing an excellent sample size. In contrast to experimental studies there are no straightforward and commonly accepted techniques to determine sample size for factor analyses (Mundfrom, Shaw, \& Ke, 2005). One approach is to rely on the absolute sample size. Estimations by Comrey and Lee (1992) suggest that a sample size of 300 is adequate, and that 1,000 or more is excellent. In general, the literature agrees that in exploratory factor analyses the higher the sample size the better (e.g. Costello \& Osborne, 2005). A different approach is to aim for a subject-to-item ratio of at least 5:1 (Gorsuch, 1983), better 10:1 or higher (Everitt, 1975; Nunnally, 1978). Our final sample of 1,108 therefore represents a size that is more than adequate, and with 27 items, gave us an excellent final subject-to-item ratio of 41:1.

Items were presented in randomized order and participants were asked to indicate to which extent they agreed with the statements on a Likert scale from 1 (strongly disagree), over 4 (neither agree nor disagree) to 7 (strongly agree). If not further specified this response scale was used for 
all established measures throughout our five studies.

We chose to conduct the study online for a number of reasons. Research suggests that data obtained via online platforms such as Amazon MechanicalTurk is of high quality (Paolacci \& Chandler, 2014) and that results are comparable to results from campus studies (Bartneck, Duenser, Moltchanova, \& Zawieska, 2015). Importantly for our purposes, it was critical to have a broad sample that is representative of the general public in terms of education background, gender, and age, as speciesism is likely to correlate with such factors. Online participants have been shown to be more diverse (Shapiro, Chandler, \& Mueller, 2013) and highly representative (Buhrmeister, Kwang, \& Gosling, 2011), more so than traditional samples (e.g. Berinsky, Huber, \& Lenz, 2012; Rand, 2012)-largely because online studies allow for the recruitment of broader population samples than the often-limited university student samples.

\section{Results}

\section{Exploratory Factor Analysis}

We first conducted Exploratory Factor Analysis (EFA) using the principal axis factors extraction method to determine the factor structure of the 27 items. Oblique direct oblimin rotation was chosen as we expected that underlying factors would correlate. The Kaiser-Meyer-Olkin (KMO) measure of sampling adequacy was .94, which is above the recommended value of .6 , indicating that individual items shared enough common variance for such an analysis. Bartlett's test of sphericity was significant: $\chi^{2}(351)=12,748.82, p<.001$. The first factor explained $34.04 \%$ of the variance (eigenvalue $=9.20$ ), the second factor $9.39 \%$ of the variance (eigenvalue $=$ 2.54 ), the third factor $5.30 \%$ of the variance (eigenvalue $=1.43$ ), the fourth factor $5.08 \%$ of the variance (eigenvalue $=1.37$ ), and the fifth factor $3.83 \%$ of the variance (eigenvalue $=1.04$ )

The scree plot displayed a clear inflexion point, which justified retaining two factors. As such, we ran a further analysis, specified to extract two factors. The first extracted factor seemed to capture our intended construct of speciesism including both abstract items and more concrete items capturing attitudes towards animal exploitation and animal rights. The second factor captured ethical vegetarianism (e.g. "It is morally wrong to eat fish").

Based on theoretical and statistical (see CFA below) considerations, we decided to retain the first factor only. It best captured the "pure" theoretical construct of speciesism, in isolation from other constructs. In this context, it is notable that factor analysis extracted speciesism and ethical vegetarianism as separate constructs. This is evidence that the two constructs are psychologically distinct. The speciesism factor and the ethical vegetarianism factor correlated negatively with each other, $r=-.35, p<.001$.

Items for the further development of the scale were selected or excluded on the basis of theoretical and statistical considerations. In particular, we focused on including items with high factor loadings while ensuring that theoretically relevant aspects of speciesism were captured by the set of items. We prioritized items that did not include empirical assumptions about the intelligence or suffering of animals to avoid confounding assumptions (e.g. items three or eight). Our set of selected items contained ten items (Table 1).

\section{[Table 1]}

\section{Confirmatory Factor Analysis}

In order to examine the model fit of the ten extracted items we performed a Confirmatory Factor Analysis (CFA) relying on maximum likelihood 
estimation in $R$ using the lavaan package (version 0.5).

We used a combination of fit indices to judge the model fit. Our primary model fit index was the Comparative Fit Index (CFI) score, which indicates how well the data fits the target model compared to an independent model that assumes uncorrelated variables. CFI is frequently reported and, in comparison to other fit indices, not unduly influenced by sample size (Fan, Thompson, \& Wang, 1999). Based on recommendations in the literature we considered a model to have an acceptable fit if its CFI score was .93 or higher (Byrne, 1994). Due to the robustness of the CFI we decided to reject any model that would not meet the required CFI standard.

For models with an acceptable fit according to CFI we furthermore considered the Tucker-Lewis Index (TLI), which is an incremental fit index and must lie above .90, and ideally above .95 (Hu \& Bentler, 1999; Marsh, Balla, \& McDonald, 1988). We also applied the more traditional Chi-square test. However, it must be noted that the Chisquare test for CFA is considered to be an unreliable fit index since it is very sensitive to sample size and will usually result in significant outcomes for sample sizes larger than 200 (Steiger, 2007). Finally, we considered the Standardized Root Mean Square Residual (SRMR), which represents the standardized discrepancy between the predicted and observed correlation and must lie below .08 to justify adequate model fit ( $\mathrm{Hu} \&$ Bentler, 1999).

A first CFA revealed an unsatisfactory model fit with a CFI of 0.88 , which lies below the required standard $(\mathrm{TLI}=.85$; SRMR = .06). Results showed that unexplained variances correlated highly among each other. This implied that certain items shared variance among each other that was not captured by general speciesism. For example, items two and four both captured the use of animals for entertainment and as such tapped into a distinct sub-form of speciesism. Similar redundancies were found between items five and seven that were both highly abstract without tapping into real-world examples, items six and nine both tapped into the domain of research use with animals, and items twelve and seventeen both captured attitudes towards animal rights. Given these redundancies, we chose to exclude items four, six, seven, and twelve from the final scale, as they did not serve any additional explanatory purpose.

A second CFA with the remaining six items was then conducted. The CFI was .98, which suggests adequate model fit. TLI was .96, which indicates excellent fit. SRMR was .07 , which is in the range of acceptable values. In contrast, to the already mentioned fit indices, the Chisquare test yielded a poor fit, $\chi^{2}(9)=52.87$, $\mathrm{p}<.001$. However, as mentioned the Chisquare test is considered to be an unreliable fit index for which reason we did not strongly weight its result but still report it for completeness sake. As such, CFA indicated that the model of the sixitem scale was an appropriate fit. Furthermore, a Kolmogorov-Smirnov test for normality suggested that the scores were normally distributed, $D(1108)=.02$, $\mathrm{p}=.20$.

Finally, we conducted a third CFA in which we tested the model fit of a twofactor model, which includes both the speciesism and ethical vegetarianism factor. The model included the six speciesism items and five ethical vegetarianism items that loaded onto the second extracted factor (Table 1). The model fit, however, was unsatisfactory $(\mathrm{CFI}=.88$; $\mathrm{TLI}=.85 ; \mathrm{SRMR}=.08)$. Only after removing items 26 and 27 the model fit became satisfactory (CFI $=.96$; TLI $=$ .94; SRMR = .05). However, due to its low item count and its non-normally distributed scores (Kolmogorov-Smirnov test for normality: $D(1108)=.11, \mathrm{p}<.001)$ we do not recommend using the ethical 
vegetarianism factor as a measurement instrument.

\section{Confirmatory Factor Analysis on a Separate Dataset}

In order to confirm our six-item onefactor solution we collected a new set of data with which to test our model. 200 US American participants took part in the study online via MTurk and received $\$ 0.70$ for taking part. Four participants did not complete and nine were excluded for failing the attention check question. This left a final sample of 187 US American participants (89 female; $M_{a s}=35.73, S D=$ 10.36). This sample size is again adequate according to the rule of thumb of aiming for a subject-to-item ratio of at least 1:10 (Everitt, 1975; Nunnally, 1978) as in our case the ratio was 31:1. Furthermore, our sample size nearly equals Jackson's (2001) recommendation to recruit a minimum of 200 participants for CFA relying on maximum likelihood estimation. Participants responded to the speciesism items and demographic questions. This new data set provided very strong evidence for the six-item model, where the CFI was .99, TLI was .99, the SRMR was .02, and even the Chi-square test yielded an acceptable fit, $\chi 2(9)=11.87, \mathrm{p}=.22$.

\section{The Speciesism Scale}

Based on a series of EFA and CFAs, we arrived at our final items to form a Speciesism Scale (Table 2). The Speciesism Scale consists of six items all loading onto a single factor. Speciesism scores were normally distributed across the sample with a mean of $3.64(S D=1.25)$ where the minimum was 1 and the maximum 7 . Reliability analyses yielded that the sixitems scale had high internal consistency, with a Cronbach's alpha of .81 .

[Table 2]

\section{Discussion}

The goal of Study 1 was the development of a theoretically informed and empirically sound Speciesism Scale. A combination of EFA, CFA, and reliability analysis supported the development of a one-dimensional scale. All six items strongly loaded onto a single speciesism factor, which had good model fit and high internal consistency, and this model was confirmed by an additional CFA conducted on a separate dataset. Most importantly, the scale fulfills all requirements that were stipulated at the beginning of the study: all items explicitly capture speciesism and the scale encompasses crucial aspects of the theoretical concept; experts in relevant fields validated all items; the scale consists of both abstract and empirical items; and does not contain items eliciting empirical and normative confounding factors.

It is interesting that speciesism and ethical vegetarianism were - despite being strongly correlated psychologically distinct factors. At first blush, this result might be surprising, as one might expect that endorsement of anti-speciesism would consistently result in endorsement of ethical vegetarianism. However, this finding is consistent with previous research on the meat paradox (Bratanova, et al, 2011; Bastian \& Loughnan, 2016). People might endorse anti-speciesism in the abstract or in domains where it does not conflict with their personal preferences, but they employ specific beliefs and practices in the context of food (i.e. carnism; Monteiro et al., 2017; Piazza et al., 2015).

\section{Study 2. Temporal Stability}

We have hypothesized that speciesism is a psychological form of prejudice analogous to other psychological forms of prejudice such as racism or sexism. If this is the case speciesism should - like other forms of prejudice - be a relatively stable construct that persists over time. Of course, like any other form of prejudice, the extent to which a person holds speciesist attitudes can fluctuate 
depending on the situation and other conditional factors. Ultimately, however, the extent to which a person holds speciesist attitudes should stay relatively stable over time because otherwise speciesism could not be considered a psychological prejudice analogous to racism or sexism, but a short-term belief connected to spontaneous emotional reactions. In order to investigate the temporal stability of speciesist attitudes, we examined the test-retest reliability of the Speciesism Scale over a period of four weeks. To the extent that speciesism does represent a stable prejudice, scores at the two times should be highly correlated.

\section{Methods}

The study consisted of two stages: a first stage in which participants completed the speciesism scale, and then a second stage four weeks later in which these same participants were invited to again complete the scale. In the first stage, 685 participants took part via MTurk and received a payment of $\$ 0.50$ for their participation. Eight participants were excluded for failing the attention check question, leaving a final sample of 677 US American participants (305 female; $M_{a x}=$ $34.37, S D=10.94)$. We conservatively assumed a response rate of around 30\% for the second stage of the study and an expected effect size (Pearson correlation coefficient) between 0.6 and 0.8 . Based on sample size calculations for test-retest analyses in the literature (Shoukri et al., 2004) we decided to aim for at least 200 responding participants in the second stage and as such aimed to recruit 680 in the first stage (given the expected 30\% response rate). Participants completed the Speciesism Scale but were not informed about the follow-up study. Other filler measures were included to distract from the speciesism items.

In the second stage four weeks later, all 677 participants were contacted again with information about the retest study. 333 US American participants (164 female;
$\left.M_{a x^{\prime}}=36.82, S D=11.51\right)$ completed the retest study (giving a higher-thanexpected response rate of $49 \%$ ), and all participants again received $\$ 0.50$ payment for taking part. No participants were excluded at this stage, and this final sample of 333 is more than adequate, exceeding minimum recommendations for test-retest analyses (Shoukri et al., 2004).

\section{Results and Discussion}

Internal consistency was high for both stages of the study with a Cronbach alpha of .89 for the first stage and .90 for the second stage of the study, andcritically-a retest analysis with the 333 cases revealed a test-retest correlation coefficient of $r=.88, p<.001$. That is, participants' scores on the Speciesism Scale were very highly correlated with their scores on the same scale four weeks later. The high test-retest reliability is an important part of establishing speciesism as a temporally stable psychological prejudice and demonstrates that speciesism-similar to racism or sexismis not just a short-term belief or emotional reaction, but a stable view that persists over time.

Although our primary purpose for this study was to consider test-retest reliability, given that for the first sample we had a sample size of 677 , we decided to subject the resulting speciesism ratings to an additional CFA to investigate if our six-item one-factor structure revealed in the two independent samples of Study 1 holds a third confirmatory test. Results confirmed once again that our six-item model had excellent fit (CFI $=0.98$, TLI $=$ $0.97, \mathrm{SRMR}=0.02$ ).

Overall, in Study 2 we provided further psychometric support for our Speciesism Scale, finding excellent fit for our model in an independent data sample and finding good test-retest reliability over time. Of course, the results from Study 2 cannot show that speciesism is a result of similar psychological processes to other forms of prejudice, only that 
speciesism can in fact be considered a stable and measurable attitude like racism and sexism. In Study 3 we turned to look at how similar speciesism is to other forms of prejudice in terms of content.

\section{Study 3. Convergent Validity}

In Study 1 we developed a new and reliable scale to measure speciesism, and in Study 2, we confirmed that speciesism scores were persistent over time. Combined, the results of Studies 1 and 2 highlight that speciesism is a stable psychological construct. Having met our first aim-to develop a reliable and valid scale to measure speciesism-we next turned to our second aim: to better understand the nature of speciesism by looking at what other attitudes speciesism is associated with, and which more general psychological orientations drive such speciesist attitudes. By doing so we sought to establish convergent validity of the Speciesism Scale.

In Study 3, equipped with our new scale, we explored whether speciesism might usefully be described as a form of prejudice by shedding light on the relationship of speciesism with other psychological constructs. We took a twopronged approach: first, we tested whether speciesism correlates with other forms of prejudice (Aim IIa); and second, we looked at whether speciesism, like other forms of prejudice, is driven by socio-ideological factors such as social dominance orientation or right-wing authoritarianism that maintain other forms of intergroup conflict (Aim IIb).

Our first aim-Aim IIa-was drawn from the personality approach to prejudice, which suggests that prejudice is typically a generalized phenomenon: a person who is high on ethnic prejudice will also be high on gender-based prejudice, and so on (Allport, 1954). For example, prejudice toward various targets tend to be significantly correlated (Akrami, Ekehammer, \& Bergh, 2011), and factor analyses yield a generalized prejudice factor explaining $50 \%$ to $60 \%$ of the variance in different forms of prejudice (Ekehammar \& Akrami, 2003). If speciesism is indeed to be usefully considered a form of prejudice, people who hold stronger speciesist attitudes should also exhibit other prejudicial attitudes.

Our second aim-Aim $\mathrm{IIb}$-is a result of the reasoning, as suggested by the SDHARM model (Dhont et al., 2016), that if speciesism is a form of prejudice it should share psychological roots with other forms of prejudice. In this way, we hoped both to further validate the Speciesism Scale by showing it to be correlated with social dominance orientation and related socio-ideological constructs, as well as providing independent support for the claims of the SD-HARM model.

As a third and more exploratory aim-Aim IIc-, we aimed to investigate the relationship between speciesism with empathic concern and actively openminded thinking. A previous study has already identified a relation between empathy levels and attitudes to animals (Taylor \& Signal, 2005) and as such we hypothesized that people higher in empathic concern would care more about the suffering of animals and subsequently endorse less speciesist attitudes. Similarly, because speciesist attitudes predominate in society, we predicted that actively open-minded people, people who are more willing to change their beliefs (Baron, 2000) and think beyond the currently accepted norms, are more likely to endorse anti-speciesism.

\section{Method and Results}

257 US American participants took part in the study online via MTurk, and received $\$ 1$ payment for their participation. Fifteen participants were excluded for failing an attention check, leaving a final sample of 242 people (110 female; $\left.M_{a s}=36.33, S D=11.88\right)$. With that, our sample size met the recommendations 
of Comrey and Lee (1992) to recruit at least 200-300 participants for scale validation. Furthermore, a review of over a hundred scale validation studies revealed that the median sample size of such studies was 121 , and so with a final sample of 242 we were confident that our sample size was more than adequate (Anthoine, Moret, Regnault, Sébille, \& Hardouin, 2014).

In the main part of the study, participants were asked to complete to the Speciesism Scale and a number of separate scales presented in a random order, which are discussed in turn along with their results below. At the end of the study participants responded to demographic questions including age, gender, education (six-step continuous scale from "less than high school degree" to "graduate degree"), income (10-step continuous scale from "under $\$ 5,000$ per year" to "over $\$ 100,000$ per year"), and whether they are vegetarian (yes or no). Median education level was "attended college" $(M=4.22, S D=1.29)$ and median annual income level was "\$25,001$\$ 35,000 "(M=5.22, S D=2.34)$.

We note that two items from the original item pool that in Study 1 were shown not to load on the main speciesism factor were included in this (and all following) studies. To ensure that our results for the main Speciesism Scale hold over and beyond the inclusion of these two items, we explored whether results changed when these two items were added to the scale. As it did not, this issue is further ignored. Due to the multiple correlation analyses we conducted with speciesism we relied on a Bonferroni adjusted alpha level of .006 per test $(.05 / 9)$ as an indicator for statistical significance (see Table 3 for all correlation coefficients).

\section{Prejudicial Attitudes}

Our first set of measures was intended to address Aim 2a: to what extent does speciesism correlate with other, prototypical forms of prejudice? To the extent that speciesism is-as philosophers have argued it to be-a form of prejudice, it should be correlated with other forms of prejudice. Specifically, we looked at three prototypical forms of prejudice: prejudice based on ethnic background or race (racism), prejudice based on gender (sexism), and prejudice based on sexual orientation (homophobia). A growing body of research has suggested that speciesism is associated with prejudice, but most of this has used simple feeling thermometer type questions (Dhont et al., 2014; 2016). In our study, therefore we drew upon this work but relied on widely used and empirically validated scales.

First, to tap racism, we used the Modern Racism Scale (McConahay, 1986). This consists of 7 items and includes items such as "Blacks are getting too demanding in their push for equal rights" (internal consistency: $\alpha=.75$ ). Second, to look at sexism we used the Modern Sexism Scale (Swim, Aikin, Hall, \& Hunter, 1995). This consists of 8 items and included items such as "Women often miss out on good jobs due to sexual discrimination" $(\alpha=$ .92). Third, to look at homophobia, we used the revised short version of the Attitudes Toward Lesbians And Gay Men Scale (Herek, 1998). This consists of 10 items including "The idea of homosexual marriages seems ridiculous to me" ( $\alpha=$ .97). To the extent that speciesism is a form of prejudice analogous to other kinds, speciesist attitudes should be associated with increased ethnic, gender, and sexuality-based prejudice, just like these types of prejudice are typically associated with one another (Pratto et al., 1994). Indeed, confirming the contention that speciesism is correlated with other forms of prejudice, we found significant positive correlations of speciesism with racism $(r=.32, p<.001)$, sexism $(r=.41, p$ $<.001)$, and homophobia $(r=.17, p<.001)$.

\section{Socio-Ideological Beliefs}

Our second set of measures were intended to address Aim 2b: to explore 
whether speciesism, like other forms of prejudice, is driven by socio-ideological factors. Four such socio-ideological factors stand out in previous research on prejudice and intergroup conflict: Social Dominance Orientation (SDO; Pratto et al., 1994); political conservatism (e.g. Jost et al., 2003); system-justification (Kay, \& Jost, 2003); and right-wing authoritarianism (RWA; Altemeyer, 1988).

We first looked at Social Dominance Orientation (SDO; Pratto et al., 1994). As discussed above, the SD-HARM (Dhont et al., 2016) model posits that SDO underpins both speciesism and humanhuman types of prejudice, and so we predicted that SDO would be correlated with speciesism and that SDO would account for the correlation between speciesism and human-human types of prejudice. SDO was measured using the SDO-6 scale (Pratto et al., 1994), which consists of 8 items including "Some groups of people are simply inferior to other groups" ( $\alpha=.93)$. Second, we looked at political conservatism, which has been previously found to correlate with speciesism (Dhont et al., 2016). We measured conservatism using a standard measure (e.g. Graham, Haidt, \& Nosek, 2009; Stern, West, Jost, \& Rule, 2013; Poteat \& Mereish, 2012) where participants indicated on two Likert scales from 1 (very liberal) to 7 (very conservative) the degree to which they identify as economically and socially conservatives respectively. The two measures were aggregated in the analysis.

Third, we looked at systemjustification (Kay, \& Jost, 2003), which to our knowledge has not been investigated in the context of speciesism before. The scale consists of 8 items including "In general, you find society to be fair" ( $\alpha=$ .86). People who score high in systemjustification tend to justify and defend the status quo, and given that the status quo places strict hierarchies amongst animals, we therefore assumed that they would also be more likely to defend the current speciesist norm. And fourth and finally, we looked at right-wing authoritarianism (RWA; Altemeyer, 1988), a construct tapping into the extent to which people adhere to established authorities and conventions and their hostility towards those who do not. The scale consists of 15 items including "The established authorities generally turn out to be right about things, while the radicals and protestors are usually just 'loud mouths' showing off their ignorance" $(\alpha=.92)$.

Results showed that, supporting predictions, speciesism was significantly correlated with SDO $(r=.42, p<.001)$, political conservatism $(r=.25, p<.001)$, system-justification $(r=.25, p<.001)$. The correlation between speciesism and RWA was positive, but not considered statistically significant under the adjusted Bonferroni alpha level of .006 $(r=.14, p=$ .03). People that were more speciesist were also more likely to endorse hierarchies between groups, report a more conservative political ideology, and more likely to engage in system justification. Recall that the SD-HARM model suggests that SDO is the common ideological root of both speciesism and human-human types of prejudice. In order to test this hypothesis we conducted partial correlation analyses between speciesism and the other measures in which we controlled for SDO. And indeed, when controlling for SDO we found that all partial correlations but sexism and empathic concern became non-significant (Table 2).

\section{Empathic concern and Actively Open- Minded Thinking}

Finally, we addressed Aim 2c: identifying the relation between speciesism and empathic concern as well as actively open-minded thinking. We used the Empathic Concern scale, which forms part of the Interpersonal Reactivity Index (IRI; Davis, 1983) and consists of 7 items such as "When I see someone being taken advantage of, I feel kind of 
protective toward them" $(\alpha=.97)$. As predicted the results revealed that speciesism correlated negatively with empathic concern $(r=-.46, p<.001)$.

Next, we looked at actively openminded thinking (Baron, 2000). The scale we relied on (Stanovich \& West, 1997) consists of the subscales dogmatic thinking, categorical thinking, flexible thinking, counterfactual thinking, and openness. In total it consists of 40 items such as "A person should always consider new possibilities" $(\alpha=.92)$. Speciesism correlated negatively with actively openminded thinking $(r=-.17, p=.01)$. This was mainly driven by dogmatic thinking $(r=.21, p<.001)$ and flexible thinking $(r=$ $-.16, p=.01)$ and less so by openness $(r=$ $.10, p=.07)$, categorical thinking $(r=.10, p$ $=.13)$ or counterfactual thinking $(r=.03, p$ $=.63$ ).

\section{Vegetarianism}

Fourteen of the 242 participants $(6 \%)$ stated that they were vegetarian, and they were more likely to disagree with speciesism than the rest of the sample, $t(240)=5.64, p<.001, d=1.77$. Like in Study 1, speciesism correlated negatively with items capturing attitudes towards vegetarianism (second extracted factor of Study 1, see Table 1), $r(240)=-.31, p<$ .001 .

\section{Demographics}

There was a significant effect of gender such that men $(M=3.82, S D=$ 1.30) were more likely to show speciesist attitudes than women $(M=2.91, S D=$ 1.26), $t(239)=5.46, p<.001, d=0.71$. The negative correlation between speciesism and age did not reach significance, $r(240)$ $=-.11, p=.08$, and there were no significant correlations between speciesism and level of education $r(247)=$ $-.02, p=.75$, or income $r(247)=.10, p=.11$.

[Table 3]

\section{Discussion}

As hypothesized, speciesism was positively associated with prejudicial attitudes such as racism, sexism, and homophobia. Speciesism was also positively associated with socioideological beliefs such as social dominance orientation, conservatism, system justification, and right-wing authoritarianism. Furthermore, speciesism was negatively associated with actively open-minded thinking and empathic concern. Note, however, that the correlations between speciesism and right-wing authoritarianism and actively open-minded thinking were relatively weak and not statistically significant under the adjusted Bonferroni alpha level of .006.

Our findings lead us to conclude that speciesism can be considered a psychological prejudice analogous to other forms of prejudice. First, our results are consistent with Allport's assumption (1954) of an underlying generalized prejudice: a person who exhibits one type of prejudice will likely also exhibit other types of prejudice, and importantly this extends to prejudice based on species membership. This suggests that there is a common component of generalized prejudice that drives different types of specific prejudicial attitudes such as racism, sexism, homophobia as well as speciesism (Akrami et al., 2011). Second, our results support the SD-HARM theory (Dhont et al., 2016), which assumes that the same ideological roots that underpin human-human forms of prejudice also underpin speciesism. More specifically, the fact that SDO accounted for the relation between speciesism and other types of prejudice supports the notion that a general endorsement of social hierarchy and inequality drives these different manifestations of prejudice. The generalized prejudice and SD-HARM hypotheses are not mutually exclusive: research has shown, for example, that the 
generalized prejudice factor is strongly related to SDO, RWA as well as empathy (Bäckström \& Björklund, 2007; McFarland, 2010) - findings that are consistent with our results.

Further, our results suggest that people who endorse views on the political right are more likely to display speciesist attitudes. Considering that speciesism is the accepted social norm in Western society, it is not surprising that those who endorse the status quo are more likely to endorse speciesism. These findings are in line with previous research showing that people who consume meat score higher on SDO and RWA scales than vegetarians (Allen \& Baines, 2002; Allen, Wilson, Ng, \& Dunne, 2000).

The observation that speciesism correlated negatively with actively openminded thinking supports our assumption that those who accept antispeciesism are more willing to think beyond contemporary social norms. And as expected, speciesism correlated negatively with empathic concern. This correlation remained strong even when controlling for SDO, which suggests that empathic concern is an additional and independent route to reach anti-speciesist attitudes. This is in line with previous research showing that in addition to SDO and RWA low empathy is one of the roots of generalized prejudice (McFarland, 2010).

As in the first study, we found that male participants were more likely to endorse speciesist views than female participants. This confirms a similar finding that women have kinder attitudes towards animals than men (for a review see Mathews \& Herzog, 1997; Herzog, et al., 1991). Notably, previous research has pointed out that meat consumption is often related to masculinity. Rothgerber (2013) has found that for some men meat consumption makes them feel like "real men". People who consume meat are perceived as more masculine (Ruby \& Heine, 2011) and meat has become a metaphor for masculinity (Rozin, Hormes, Faith, \& Wansink, 2012).

\section{Study 4. Helping via Donation Allocations}

Thus far we have argued that speciesism is a psychological construct and developed a valid and reliable measure of speciesism (Study 1); confirmed that speciesist attitudes are consistent over time (Study 2); and shown that speciesism can usefully be considered a form of prejudice, being associated with other forms of prejudice and sharing common ideological roots with them (Study 3). Next, we turned to the more behavioral effects that speciesist attitudes might have by looking at whether speciesism can predict decision-making in the context of charitable giving. Previous work has exclusively focused on selfreport items relating to feelings or beliefs about the relationship between humans and animals. In Studies 4 and 5 we addressed our third aim: to determine whether speciesist attitudes translate into observable decision-making and behavior.

Our initial assumption was that participants who scored high for speciesism would be willing to allocate more money to a charity that helps individuals of a "superior" species (rather than an "inferior" one). In particular, we hypothesized that speciesism would drive participants to a) help humans more than animals, b) help severely mentally disabled humans more than chimpanzees, and c) help dogs more than pigs. These examples capture three crucial aspects of speciesism (as defined in philosophy) in our society: a) the view that animals are morally inferior to humans; b) the view that (a) is true even when the humans and animals in question have similar cognitive abilities; and c) the view that some animals are morally inferior to other animals (even when these animals have similar cognitive and emotional capabilities). As such, this study also 
serves as a philosophically grounded validation of our Speciesism Scale. The final items of the scale do not directly capture aspects (b) and (c). Yet, if it is true that there is a single psychological construct that captures speciesism in its entirety (as defined in philosophy), we should expect the scale to predict aspects (b) and (c) in addition to aspect (a).

With these parameters in mind, we hypothesized that speciesism would be able to predict donation allocations above and beyond established discrimination and pro-sociality measures such as SDO and empathic concern. One of the conclusions reached in our third study was that speciesism can be considered a sub-type of SDO as proposed by SDHARM (Dhont et al., 2016). In this study we aim to show that speciesism despite its strong relation to SDO is able to explain discriminatory behavior above and beyond it. We would expect speciesist behavior to particularly be observed in contexts in which individuals of different species are contrasted. In such contexts, we would expect speciesism to give more specific predictions than the more generalized concept of SDO.

Finally, we were also interested in the link between speciesism and people's explicit beliefs about the intelligence and sentience of animals. It is possible, for example, that people are not treating certain animals differently because of speciesism, but simply because they believe that they are less intelligent or less able to feel pain. We hypothesized that explicit beliefs about intelligence and sentience were likely to be associated with speciesist views, but would not be able to fully explain the differential treatment between different species. Instead, we expect that speciesism itself-moral discrimination based on species membership alone-would be able to explain differences in donation allocations above and beyond explicit beliefs about intelligence and sentience.

\section{Method}

\section{Participants}

140 US American participants took part in the study online via MTurk (110 female; $\left.M_{a s e}=33.60, S D=10.54\right)$, and received $\$ 1.70$ for their participation. All participants successfully passed the two attention check questions, so nobody was excluded. We deemed a sample size of 140 participants appropriate, as our a priori power analysis showed that 135 participants were required to detect an anticipated medium effect size of $\mathrm{f}=0.15$, taking an alpha of .05 and power of .80 (Soper, 2017; Cohen, Cohen, West, \& Aiken, 2003).

\section{Materials and Procedure}

Participants were presented with three independent scenarios of donation allocation questions in a random order. In each scenario, one of the charities focused on helping a "superior" type of species (humans, mentally severely disabled humans, or dogs), while the other focused on helping an "inferior" type of species (animals, chimpanzees, or pigs).

The two charities were presented as follows in the first donation scenario:

Charity A: This charity focuses on helping animals. On average, \$10 will keep one individual from pain and suffering for one day.

Charity B: This charity focuses on helping humans. On average, \$10 will keep one individual from pain and suffering for one day.

In the second scenario the words "animals" and "humans" were replaced by "chimpanzees" (Charity A) and "mentally severely disabled humans" (Charity B), in the third scenario by "pigs" (Charity A) and "dogs" (Charity B) respectively. In all three scenarios, participants were asked to allocate 100 donation points, which were independent of participants' payment, between the two charities. They were told that their decisions would have a real-world effect, 
as the experimenters would donate $\$ 100$ to the charities in proportion the responses received from all participants (which we did).

After participants responded to the donation allocation questions, they were presented with the Speciesism Scale and the following additional measures: Social Dominance Orientation was included because of the strong link found to speciesism in the previous study. Attitudes Toward Disabled Persons (Yuker, Block, \& Young, 1970; from now on referred to as ableism) was included in order to control for discrimination against disabled people in the donation case involving mentally severely disabled humans. Empathic concern (IRI; Davis 1983) was included because it showed a strong negative correlation with speciesism in the previous study. Perspective taking, Other-oriented moral reasoning and Mutual concerns moral reasoning scales of the pro-social personality battery (Penner, Fritzsche, Craiger, \& Freifeld, 1995) were included because we assumed that these prosociality traits could potentially play a role in reducing prejudice.

Further, participants were presented with a list of six different types of individuals: humans in general, animals in general, chimpanzees, mentally severely disabled humans, dogs, and pigs. First, participants were asked to indicate to which extent each type of individual was capable of experiencing physical pain and fear (aggregated and from now on referred to as 'suffering capability'). Then, participants were asked to indicate how intelligent they perceived each type of individual to be. By framing this task as a biology quiz, participants were told that they should be as accurate as possible in their assessment of these traits. Finally, participants were asked to respond to demographic items.

\section{Results}

People allocated significantly more to the "superior" than to the "inferior" species charities in all three cases (Figure 1 ). As the allocations to the respective charities were negatively proportionate to each other, one sample t-tests were conducted to compare whether allocations significantly differed from an equal distribution of 50 donation points each. Participants allocated more to help humans $(M=67.92, S D=26.36)$ than animals $(M=32.08, S D=26.36), t(139)=$ $8.04, p<.001$, more to help mentally severely disabled humans $(M=72.46, S D$ $=23.61)$ than to chimpanzees $(M=27.54$, $S D=23.61), t(139)=11.26, p<.001$, and more to help dogs $(M=68.57, S D=31.43)$ than pigs $(M=31.43, S D=19.43), t(139)=$ $-11.29, p<.001$.

Speciesism correlated positively with SDO $(r=.35, p<.001)$ and negatively with empathic concern $(r=-.26, p<.001)$ and other-oriented $(r=-.23, p<.05)$ and mutual concern moral reasoning $(r=-.20$, $p<.05)$. However, it did not correlate significantly with ableism $(r=-.04, p=.60)$ and perspective taking $(r=-.09, p=.32)$. Speciesism correlated negatively with most measures of beliefs about suffering capability and intelligence of animals (but not humans), and strongest for members of "inferior" species (Table 4). Participants believed that humans were more intelligent $(t(139)=8.25, p<.001)$ and more capable of suffering $(t(139)=26.63, p$ $<$.001) than animals (Table 4). However, despite allocating more money to help mentally severally disabled humans than chimpanzees, they believed the former were less intelligent $(t(139)=4.98, p<$ .001) and - although only on a descriptive level - less capable of suffering $(t(139)=1.71, p=.09)$ than the latter. Also, participants believed that dogs were more intelligent $(t(139)=2.22, p$ $=.03)$ and more capable of suffering $(t(139)=5.58, p<.001)$ than pigs. 
[Table 4]

Hierarchical regression analyses were conducted in order to assess whether speciesism is able to uniquely predict participants' allocations. Demographics (gender, age, education, income) were entered at Step 1; Social psychological discrimination and pro-sociality constructs (SDO, empathic concern, perspective taking, other-oriented moral reasoning, mutual concerns moral reasoning, and ableism in the case involving mentally severely disabled humans) were entered at Step 2; Beliefs about suffering capability and intelligence of the respective two entities per case were entered at Step 3; Speciesism was entered at Step 4.

Tests of collinearity indicated that multicollinearity was not a concern (all variance inflation factors (VIF) were below 2.7). The analyses revealed that speciesism was able to predict the amount of allocations in all three cases significantly above and beyond demographic, discrimination and prosociality measures and perceived suffering capability and intelligence. Thus, despite the fact that people with high scores on speciesism believed animals' suffering capability and intelligence were reduced, speciesism significantly predicted allocations above and beyond these beliefs (Table 5).

\section{[Table 5]}

\section{Discussion}

In Study 4, we looked at whether speciesist attitudes translate into decisions about donation allocations. On average, participants allocated higher donations to a) a charity focusing on helping humans than to a charity focusing on helping animals; b) a charity focusing on helping mentally severely disabled humans than to a charity focusing on helping chimpanzees; and c) a charity focusing on helping dogs than to a charity focusing on helping pigs. Speciesism was able to explain these allocation decisions above and beyond demographic measures; discrimination and pro-sociality measures (including SDO and empathic concern); and measures of explicit beliefs about suffering capability and intelligence. We conclude that speciesism makes a unique contribution to our understanding of how people judge and treat individuals of different species over established social and psychological constructs. It uniquely captures an important but neglected aspect of discrimination and pro-sociality. These findings further demonstrate the (philosophical) content validity of the Speciesism scale. The psychological construct that the Speciesism Scale measures reliably predicts all major aspects of speciesism in our society as defined in philosophy.

People who displayed speciesist attitudes were more likely to believe that animals have a reduced capability to suffer (particularly animals of "inferior" species) as well as have lower intelligence. This is consistent with studies that have found people tend to 'de-mentalize' animals classified as food (Bastian, Loughnan, Haslam \& Radk, 2012) and that the extent of moral value they attribute to animals is related to the animal's degree of intelligence and sentience (Piazza \& Loughnan, 2016). Our study, however, did not investigate the causal direction of this association. It could be that speciesism drives people to attribute lower mental capabilities to animals or that lower attributed mental capabilities drive speciesism. In the present study, people's explicit beliefs of the ability to suffer and the level of intelligence did explain their donation allocations to some extent. However, speciesism was able to explain it above and beyond these beliefs in all three cases. An interesting finding was that our study showed that in some cases people morally value individuals of certain species less 
than others even when knowing that the former (e.g. chimpanzees) are more intelligent and more sentient than the latter (e.g. mentally severely disabled humans). These findings confirm our hypothesis that the differential treatment of animals is not motivated by people's explicit beliefs about sentience and perceived intelligence alone; it is at least in parts motivated by speciesism.

It is important to note that participants in our study were explicitly asked to rate the suffering capability and level of intelligence as biologically accurate as possible. In real life settings, in contrast, motivated reasoning can distort these beliefs - as demonstrated, for example, by studies investigating the meat paradox (Bastian \& Loughnan, 2017). People's perceptions of these mental properties are thus very flexible and depend on the context and motivational incentives. As such, even though our study demonstrates that differential treatment of individuals of different species cannot be fully explained by people's explicit and accuracy-motivated beliefs about the their mental capabilities, it is still possible that people's intuitive and biased perceptions significantly drive this tendency.

A possible criticism of the study is that even though participants were aware of the fact that their decisions were not just merely hypothetical, they did not have to invest personal resources in order to help the respective individuals. Instead, they decided how to allocate the available resources of the experimenter. In this light, their responses are better described as resource allocation or decision-making, but not necessarily as truly behavioral. In the next study, we aimed to address this issue by relying on a response technique, which required participants to invest their personal resources.

\section{Study 5. Helping via Time Investment and Food choice}

In Study 4, we demonstrated that speciesism predicts decision-making about donation allocations above and beyond other related psychological constructs. We conducted Study 5 with three purposes in mind. First and foremost, we aimed to replicate the finding that speciesism is able to predict helping. Second, instead of decisions regarding allocations of donations, we instead asked participants in this study whether they would invest their personal time to help individuals, and we explored whether speciesism predicts food choices. In doing so we introduce measures that are clearly behavioral. Third, we aimed to confirm that speciesism was able to predict real-world behavior in an offline, university context relying on a student sample.

In this study, we asked participants to read promotional material from a charity and asked for their feedback on how it could be improved. Each participant had to choose from two charities; one focused on helping animals and the other on helping humans. We hypothesized that participants scoring low on speciesism would be more likely to invest time in the animal charity. We further hypothesized that speciesism would be able to predict which charity participants helped above and beyond social dominance orientation, empathic concern, perceived suffering capability and intelligence of the type of individuals, and demographic data.

We also included an exploratory test related to food choices. At the end of the study, participants could choose either a meat snack or a vegetarian snack as an additional reward for participating in the study. Based on our findings from the previous studies showing that speciesism correlates negatively with ethical vegetarianism we hypothesized that those participants scoring high in speciesism would be more likely to choose the meat 
snack. This exploratory test can be seen as a proxy for meat consumption but it should be interpreted with caution as we measured food choice at a certain point in time only, not general meat consumption.

\section{Method}

\section{Participants}

102 students from a British university took part in the study and received a payment of $£ 5$ for their participation. Three participants were excluded for failing an attention check, leaving a final sample of 99 students (55 female; $M_{\text {ase }}=$ $25.52, S D=4.88)$. This sample size meets the recommendation by Long (1997), who suggests that a minimum sample of 100 should be considered for logistic regression, and our sample size is comparable to work by Crimston et al. (2016), who conducted a structurally very similar study to ours and recruited the same number of participants as we did.

\section{Materials and Procedure}

Participants completed the study in "paper \& pencil" form. They first read a general information sheet and signed a consent form. They then completed the Speciesism Scale, SDO scale, and Empathic Concern scale. Next, they were asked to indicate their beliefs in the intelligence and suffering capability of humans, chimpanzees and dogs. And finally, participants responded to demographic questions (age, gender, and study subject).

Our method for measuring participants' willingness to invest time to help a certain cause was inspired by Crimston et al. (2016). On a further sheet, participants were given instructions about a seemingly unrelated task. Participants were informed that they should provide feedback to one of two non-profit organizations (from now on referred to as charity) on how to improve their campaigns. They were told that both charities were specifically seeking feedback from students.
The two charities were described as follows:

The Nonhuman Rights project: The Nonhuman Rights Project, an organization working towards achieving actual legal rights for chimpanzees.

Homeless Shelters: Homeless Shelters, an organization providing temporary residence for people who can no longer afford to pay rent themselves.

Participants were presented with two sealed envelopes labeled with the respective names of the charities. Promotional material from the charities was contained inside the envelope. Participants were instructed to open one envelope only, and to provide written feedback about the campaign. Participants were told that their feedback would be forwarded to the charity of their choice.

At the end of the study, after receiving the payment, participants were offered a snack as an additional reward. They were presented with two meat options (beef jerky, pork crackling) and two vegetarian options that clearly did not include any animal products (salted peanuts, rice crackers) and were asked to choose one.

\section{Results}

As predicted, participants who chose to invest their time to help the animal charity (Non-Human Rights Project) scored significantly lower on speciesism $(\mathrm{N}=33, M=2.73, S D=.96)$ than those who chose the human charity (Homeless Shelters) $(\mathrm{N}=66, M=3.31, S D=.83), t(97)$ $=-3.16, p=.002$. However, participants who chose to help Homeless Shelters scored higher on empathic concern $(M=$ $5.58, S D=.75)$ and lower on SDO $(M=$ $2.14, S D=1.04)$ than participants who chose the animal charity (empathic concern: $M=5.18, S D=.89 t(97)=-2.32, p$ $=.02$, SDO: $M=2.72, S D=.89 t(97)=2.76$; $p=.01)$. Notably, SDO was left skewed and therefore not normally distributed.

Hierarchical logistic regression analyses were conducted in order to assess whether speciesism was able to 
predict participants' choice of the charity above and beyond the other measures. Demographics (gender, age, study subject) were entered at Step 1; SDO and empathic concern were entered at Step 2; Beliefs about suffering capability and intelligence of chimpanzees and humans were entered at Step 3; Speciesism was entered at Step 4. The analyses revealed that speciesism was able to predict participants' timeinvestment choices significantly above and beyond all other factors listed. Results are shown in Table 6.

\section{[Table 6]}

Further, participants who chose the meat snack $(\mathrm{N}=26, M=3.47, S D=.90)$ scored also significantly higher on speciesism than participants who chose the vegetarian snack $(\mathrm{N}=72, M=2.98, S D$ $=.88), t(96)=-2.40, p=.018$. Hierarchical logistic regression analysis predicting the snack participants chose analogously to the above analysis was close to being significant, $R^{2}=.23, p=.07$.

\section{Discussion}

This study demonstrated that speciesism is able to predict how people will invest their time when faced with a choice between helping animals or humans. After controlling for demographics, empathic concern, SDO, and beliefs about suffering capability and intelligence of humans and chimpanzees, each one-point increase in speciesism increased the likelihood of people choosing to help the human charity by $195 \%$. Significant results supporting this finding were also found in an online pilot study $(\mathrm{N}=51)$ we conducted prior to the student sample study.

Interestingly, people who chose the animal charity showed less empathic concern than people who chose the human charity. Empathic concern, therefore, seems to be a stronger predictor for helpful behavior towards humans than towards animals (when one is only faced with these two options only). This is in spite of the negative correlation between speciesism and empathic concern. One possible explanation for this result is that people feel empathic concern to those who are close to them, and people feel more closely connected to other humans than to animals. Another explanation might be that fighting homelessness triggers more empathy than establishing animal rights because the former is perceived as more imminent and more directly tractable than the latter.

Other results were also puzzling at first. For example, people who chose to help the animal charity also scored higher in SDO than people who chose to help the human charity. At first glance, this appears inconsistent with our previous findings. However, we should be cautious to attribute much weight to this result, as SDO was strongly left skewed in the university student sample. In contrast, in the online pilot study SDO and empathic concern were normally distributed and no correlations between the charity chosen and SDO and empathic concern were revealed.

This study further demonstrated that speciesism can predict real-world food choices. The lower people scored on speciesism, the more likely they were to choose the vegetarian snack. This finding confirms the result of the online pilot study in which participants were asked a hypothetical question about what food they would choose. The food-choice element of the study was exploratory, and there were many other factors that could have affected participants' choice of snack. These might include the social demand effect, different tastes, and the time of day, among others. A further limitation of this study was that we did not control for vegetarianism. Due to the relation between speciesism and vegetarianism, it is not clear to which extent food choices were driven by speciesism versus vegetarianism. However, given that only $6 \%$ of US participants of Study 1 indicated 
that they were vegetarian, and recent polls suggest only $2 \%$ of the British public is consistently vegetarian (Bates et al., 2014), only little variance in food choices could have been explained by vegetarianism alone. Given that $74 \%$ of our participants chose the vegetarian snack, yet estimates suggest only a small fraction of the population to be vegetarian, it seems clear that many non-vegetarians must have chosen the vegetarian snack and there are many reasons for why this might belower scores in speciesism is likely to be one of them. Future research can hopefully shed more light on the relation of speciesism, vegetarianism, carnism, and actual food choices.

A general methodological limitation of the study is the possibility that demand effects or consistency motives could have driven the correlation between responses to the scale and responses to the tasks. Participants might have guessed what the aim of the study was after responding to the scale and might have been motivated to remain consistent in the next task. Future studies could attempt to alleviate this problem by trying to obfuscate the purpose of the study, introducing time delays between the tasks, or by other means.

\section{General Discussion}

Throughout its history, speciesism has been a concept largely confined to philosophy. Ultimately, however, speciesism is a hypothesis about human psychology; it is the assumption that people morally discriminate against individuals on the basis of their species membership. The purpose of this paper is to transition speciesism from a philosophical hypothesis to a matter of empirical psychological investigation. These investigations have only just begun in recent years and with this paper we make the following four contributions to that transition.
First, we describe the philosophy of speciesism and introduce it as a psychological phenomenon, suitable for empirical investigation. Speciesism has been purported to be a reliable form of prejudice analogous to racism and sexism, and yet the empirical claims behind this have received little attention so far.

Second, we present the Speciesism Scale: A theoretically driven and empirically validated explicit measure of speciesism with high internal consistency and test-retest reliability. This scale confirms that speciesism is an accurately measurable, stable form of prejudice with high interpersonal differences.

Third, we demonstrate that, as originally proposed by philosophers, speciesism can be considered a form of prejudice. We have found that speciesism is psychologically related to humanhuman types of prejudice such as racism, sexism, and homophobia. This is consistent with the generalized prejudice theory, which assumes that prejudice towards various targets is significantly correlated and can be explained by an underlying generalized prejudice factor (Akrami, Ekehammer, \& Bergh, 2011). Our finding that speciesism is strongly related to SDO confirms the SD-HARM model (Dhont et al., 2014), which assumes that speciesism and human-human types of prejudice are underpinned by the same socio-ideological beliefs, namely a general endorsement of social hierarchy and inequality. The fact that speciesism shares these psychological properties with other phenomena we refer to as prejudice seems to strengthen the case that speciesism can be referred to as prejudice as well. We note that in comparison to human-human forms of prejudice, speciesism is the dominant and explicitly accepted social norm and ideology in current Western societies. Consequently, people who endorse the current status quo and people on the political right tend to score high on speciesism, whereas actively openminded thinking seems to facilitate 
questioning that norm. We also identified lower levels of empathic concern as an additional factor associated with speciesism.

Fourth, we demonstrate that speciesism can predict behavior above and beyond existing constructs. In doing so, we believe we are the first to systematically show effects of speciesist attitudes on actual, observable behavior. In two studies we found that speciesism predicts people's willingness to help humans and "superior" animals such as dogs (rather than "inferior" animals such as pigs), in terms of allocating donation money and investing time. We also found that speciesism predicts people's (meat vs. vegetarian) food choices. This indicates that speciesism captures an important but neglected aspect of both discrimination and prosociality.

\section{Limitations and future research}

Our investigation of speciesism focused on the general tendency to morally discriminate between individuals on the basis of their species membership. However, we did not explicitly analyze how this occurs. It is possible that-in line with research on stereotypes and social categorizations (Haslam, 1997)—people place individuals of certain species into different categories such as food, pets, entertainment, equipment, pest, wild animals, humans, etc. These culturally and historically contingent categories might define the general connotation, perceptions, values, and common properties associated with their individuals. For example, animals in the food category (e.g. cows) seem to be associated with low moral value as well as perceptions of low mental capabilities. Animals of the pest category (e.g. rats) seem furthermore to be associated with disgust-eliciting characteristics such as being dirty. The categories ultimately define (or are defined by) how we relate to the respective individuals. And while usually whole species are placed into certain categories (i.e. speciesism), exceptions can be made; for instance, one's personal pet pig will be placed into a different category than all other pigs. Future research will hopefully further investigate the specifics of the different kinds of categories that speciesism seems to rely on.

Similarly, more research is needed to understand the cognitive mechanisms that facilitate speciesist attitudes and practices. In this regard, it is likely that the psychological process of moral disengagement (Bandura, 1999) plays a critical role. Bandura's theory of moral disengagement proposes that cognitive restructuring mechanisms allow us to view inhumane practices as benign by disabling moral self-condemnation. These mechanisms may include moral justification, euphemistic language, displacement of responsibility, dehumanization, and a disregard for the victims' suffering. Moral disengagement theory has not yet been applied to speciesism, but it is a plausible explanation for tolerating practices such as factory farming (Graça, Calheiros, \& Oliveira, 2016).

Moral philosophers have reasoned that anti-speciesists are morally compelled to adopt ethical vegetarianism (Singer, 1975; 1979). Descriptively, however, we have found that empirically this is not always the case. People do not consistently bridge the gap between caring about animals and consuming animal products (i.e. meat paradox). Our results from Studies 1 and 3 suggest that speciesism and ethical vegetarianism are psychologically distinct to some extent. Overall, however, the two are strongly linked and indeed as Study 5 suggests speciesism predicts whether people choose to eat meat or a vegetarian option. Carnism has been suggested as a major ideological driver of the continuation of meat consumption in our society (Monteiro et al., 2017). Future studies in this area will now be able to use the 
Speciesism Scale to investigate the relations and causal mechanisms between speciesism, carnism and the meat paradox with greater rigor and accuracy.

Further research is needed on how speciesism varies between cultures. Amiot and Bastian (2015) have summarized existing studies that may help to point the way. Their work focused on cross-cultural attitudes towards animals. They found, for example, that attitudes towards pet keeping vary strongly between cultures. In order for the Speciesism Scale to facilitate cross-cultural research, however, it might need to be adapted for cultures where certain animals are categorized differently to Western norms.

Many more avenues for future research are yet to be discovered. Despite the apparent ubiquity of speciesism in our every-day lives and despite the fact that speciesism is a well-known phenomenon to philosophers, speciesism is hugely under-investigated in the field of social, personality, and moral psychology. We hope that this paper can transfer some of the energy with which psychology has pursued human-human discrimination onto the so far neglected area of humananimal discrimination.

Lucius Caviola, Jim A. C. Everett, and Nadira S. Faber, Department of Experimental Psychology and Oxford Uehiro Centre for Practical Ethics, University of Oxford.

This project was supported by a grant of the Oxford Martin School (Oxford Martin Programme on Collective Responsibility for Infectious Disease), awarded to Nadira Faber. We thank Oscar Horta, Guy Kahane, Adriano Mannino, Brian Parkinson, Peter Singer, Elliot Teperman, and Steven Wise for their helpful comments and suggestions. We also thank Tanya Terzieva for her assistance in collecting the data.

Correspondence concerning this article should be addressed to Nadira S. Faber, Oxford Uehiro Centre for Practical Ethics, Suite 8, Littlegate House, St Ebbe's Street, Oxford OX1 1PT, United Kingdom. E-mail: nadira.faber@psy.ox.ac.uk 


\section{References}

Akrami, N., Ekehammar, B., \& Bergh, R. (2011). Generalized prejudice: Common and specific components. Psychological Science, 22(1), 57-59.

Allen, M. W., \& Baines, S. (2002). Manipulating the symbolic meaning of meat to encourage greater acceptance of fruits and vegetables and less proclivity for red and white meat. Appetite, 38(2), 118130.

Allen, M. W., Wilson, M., Ng, S. H., \& Dunne, M. (2000). Values and beliefs of vegetarians and omnivores. The Journal of Social Psychology, 140(4), 405-422.

Allport, G. (1954). The nature of prejudice. Reading, MA: Addison-Wesley.

Altemeyer, B. (1988). Enemies of freedom: Understanding right-wing authoritarianism. Jossey-Bass.

Amiot, C. E., \& Bastian, B. (2015). Toward a psychology of human-animal relations. Psychological Bulletin, 141(1), 6.

Anthoine, E., Moret, L., Regnault, A., Sébille, V., \& Hardouin, J. B. (2014). Sample size used to validate a scale: a review of publications on newly-developed patient reported outcomes measures. Health and Quality of Life Outcomes, 12(1), 2.

Bäckström, M., \& Björklund, F. (2007). Structural modeling of generalized prejudice: The role of social dominance, authoritarianism, and empathy. Journal of Individual Differences, 28(1), 10-17.

Bandura, A. (1999). Moral disengagement in the perpetration of inhumanities. Personality and Social Psychology Review, 3(3), 193-209.

Baron, J. (2000). Thinking and deciding. Cambridge University Press.

Bartneck, C., Duenser, A., Moltchanova, E., \& Zawieska, K. (2015). Comparing the similarity of responses received from studies in Amazon's Mechanical Turk to studies conducted online and with direct recruitment. PloS one, 10(4), e0121595.
Bastian, B., \& Loughnan, S. (2017). Resolving the meat-paradox: A motivational account of morally troublesome behavior and its maintenance. Personality and Social Psychology Review, 21(3), 278-299.

Bastian, B., Costello, K., Loughnan, S., \& Hodson, G. (2012). When closing the human-animal divide expands moral concern: The importance of framing. Social Psychological and Personality Science, 3(4), 421-429.

Bastian, B., Loughnan, S., Haslam, N., \& Radke, H. R. (2012). Don't mind meat? The denial of mind to animals used for human consumption. Personality and Social Psychology Bulletin, 38(2), 247-256.

Bates, B., Lennox, A., Prentice, A., Bates, C. J., Page, P., Nicholson, S., \& Swan, G. (Eds.). (2014). National Diet and Nutrition Survey: Results from Years 1, 2, 3 and 4 (combined) of the Rolling Programme (2008/2009-2011/2012): a Survey Carried Out on Behalf of Public Health England and the Food Standards Agency. Public Health England.

Bentham, J. (1789/1961). An introduction to the principles of morals and legislation. In Utilitarianism (pp. 7-398). Garden City, NY: Doubleday.

Berinsky, A. J., Huber, G. A., \& Lenz, G. S. (2012). Evaluating online labor markets for experimental research: Amazon.com's Mechanical Turk. Political Analysis, 20(3), 351-368.

Bilewicz, M., Michalak, J., \& Kamińska, O. K. (2016). Facing the edible. The effects of edibility information on the neural encoding of animal faces. Appetite, 105, 542-548.

Bratanova, B., Loughnan, S., \& Bastian, B. (2011). The effect of categorization as food on the perceived moral standing of animals. Appetite, 57(1), 193-196.

Broom, D. M., Sena, H., \& Moynihan, K. L. (2009). Pigs learn what a mirror image represents and use it to obtain information. Animal Behaviour, 78(5), 1037-1041. 
Brown, R. (2011). Prejudice: Its social psychology. John Wiley \& Sons.

Buhrmester, M., Kwang, T., \& Gosling, S. D. (2011). Amazon's Mechanical Turk a new source of inexpensive, yet highquality, data?. Perspectives on Psychological Science, 6(1), 3-5.

Byrne, B. M. (1994). Structural equation modeling with EQS and EQS/Windows: Basic concepts, applications, and programming. Sage.

Cohen, J., Cohen, P., West, S. G., \& Aiken, L. S. (2013). Applied multiple regression/correlation analysis for the behavioral sciences. Routledge.

Comrey, A. L., \& Lee, H. B. (1992). A First Course in Factor Analysis. Hillsdale, NJ: Erlbaum.

Costello, A. B., \& Osborne, J. W. (2005). Best practices in exploratory factor analysis: Four recommendations for getting the most from your analysis. Practical Assessment, Research \& Evaluation, 10(7), 1-9.

Costello, K., \& Hodson, G. (2009). Exploring the roots of dehumanization: The role of animal-human similarity in promoting immigrant humanization. Group Processes E Intergroup Relations.

Costello, K., \& Hodson, G. (2014). Explaining dehumanization among children: The interspecies model of prejudice. British Journal of Social Psychology, 53(1), 175197.

Crimston, D., Bain, P. G., Hornsey, M. J., \& Bastian, B. (2016). Moral expansiveness: Examining variability in the extension of the moral world. Journal of Personality and Social Psychology, 111(4), 636.

Davis, M. H. (1983). Measuring individual differences in empathy: evidence for a multidimensional approach. Journal of Personality and Social Psychology,44(1), 113.

Dhont, K., \& Hodson, G. (2014). Why do rightwing adherents engage in more animal exploitation and meat consumption?. Personality and Individual Differences, 64, 12-17.
Dhont, K., Hodson, G., \& Leite, A. C. (2016). Common Ideological Roots of Speciesism and Generalized Ethnic Prejudice: The Social Dominance Human-Animal Relations Model (SDHARM). European Journal of Personality, 30(6), 507-522.

Dhont, K., Hodson, G., Costello, K., \& MacInnis, C. C. (2014). Social dominance orientation connects prejudicial human-human and humananimal relations. Personality and Individual Differences, 61, 105-108.

Diamond, C. (1978). Eating meat and eating people. Philosophy, 53(206), 465-479.

Duckitt, J., \& Sibley, C. G. (2007). Right wing authoritarianism, social dominance orientation and the dimensions of generalized prejudice. European Journal of Personality, 21(2), 113-130.

Ekehammar, B., \& Akrami, N. (2003). The relation between personality and prejudice: a variable-and a personcentred approach. European Journal of Personality, 17(6), 449-464.

Everitt, B. S. (1975). Multivariate analysis: The need for data, and other problems. The British Journal of Psychiatry, 126(3), 237240.

Fan, X., Thompson, B., \& Wang, L. (1999). Effects of sample size, estimation methods, and model specification on structural equation modeling fit indexes. Structural Equation Modeling: A Multidisciplinary Journal, 6(1), 56-83.

Gade, D. W. (1976). Horsemeat as human food in France. Ecology of Food and Nutrition, 5(1), 1-11.

Gorsuch, R. L. (1983). Factor analysis (2nd ed.). Hillsdale, NJ: Erlbaum.

Graça, J., Calheiros, M. M., \& Oliveira, A. (2016). Situating moral disengagement: Motivated reasoning in meat consumption and substitution. Personality and Individual Differences, 90, 353-364.

Graham, J., Haidt, J., \& Nosek, B. A. (2009). Liberals and conservatives rely on different sets of moral foundations. 
Journal of Personality and Social Psychology, 96(5), 1029.

Haslam, N. (2006). Dehumanization: An integrative review. Personality and Social Psychology Review, 10(3), 252-264.

Haslam, S. A. (1997). Stereotyping and social influence: Foundations of stereotype consensus.

Herek, G. M. (1998). Attitudes toward lesbians and gay men scale. Handbook of sexuality-related measures, 392-394.

Herzog Jr, H. A., Betchart, N. S., \& Pittman, R. B. (1991). Gender, sex role orientation, and attitudes toward animals. Anthrozoös, 4(3), 184-191.

Horta, O. (2010). What is speciesism?. Journal of Agricultural and Environmental Ethics, 23(3), 243-266.

Hu, L. T., \& Bentler, P. M. (1999). Cutoff criteria for fit indexes in covariance structure analysis: Conventional criteria versus new alternatives. Structural Equation Modeling: a Multidisciplinary Journal, 6(1), 1-55.

Jackson, D. L. (2001). Sample size and number of parameter estimates in maximum likelihood confirmatory factor analysis: A Monte Carlo investigation. Structural Equation Modeling, 8(2), 205-223.

Joy, M. (2011). Why We Love Dogs, Eat Pigs, And Wear Cows: An Introduction to Carnism. Conari press.

Kagan, S. (2016). What's Wrong with Speciesism? (Society for Applied Philosophy Annual Lecture 2015). Journal of Applied Philosophy, 33(1), 1-21.

Kahane, G., Everett, J. A., Earp, B. D., Farias, M., \& Savulescu, J. (2015). 'Utilitarian' judgments in sacrificial moral dilemmas do not reflect impartial concern for the greater good. Cognition, 134, 193-209.

Kant, I. (1785/1964). Groundwork of the Metaphysic of Morals. HJ Paton. New York: Harper \& Row, 4, 420-426.

Kay, A. C., \& Jost, J. T. (2003). Complementary justice: effects of "poor but happy" and" poor but honest" stereotype exemplars on system justification and implicit activation of the justice motive. Journal of Personality and Social Psychology, 85(5), 823.

Kozak, M. N., Marsh, A. A., \& Wegner, D. M. (2006). What do I think you're doing? Action identification and mind attribution. Journal of Personality and Social Psychology, 90(4), 543.

Loughnan, S., Bastian, B., \& Haslam, N. (2014). The psychology of eating animals. Current Directions in Psychological Science, 23(2), 104-108.

Loughnan, S., Haslam, N., \& Bastian, B. (2010). The role of meat consumption in the denial of moral status and mind to meat animals. Appetite, 55(1), 156-159.

Low, P., Panksepp, J., Reiss, D., Edelman, D., Van Swinderen, B., Low, P., \& Koch, C. (2012). Cambridge Declaration on Consciousness in Non-Human Animals.

Marsh, H. W., Balla, J. R., \& McDonald, R. P. (1988). Goodness-of-fit indexes in confirmatory factor analysis: The effect of sample size. Psychological Bulletin, 103(3), 391.

Mathews, S., \& Herzog, H. A. (1997). Personality and attitudes toward the treatment of animals. Society $\mathcal{E}$ Animals, 5(2), 169-175.

McConahay, J. B. (1986). Modern racism, ambivalence, and the modern racism scale. InJ. F. Dovidio \& SL Gaertner (Eds.), Prejudice, Discrimination, and racism (pp. 91-125).

McFarland, S. (2010). Authoritarianism, social dominance, and other roots of generalized prejudice. Political Psychology, 31(3), 453-477.

Mendl, M., Held, S., \& Byrne, R. W. (2010). Pig cognition. Current Biology, 20(18), R796R798.

Mill, J. S. (1861). Considerations on Representative Democracy. Parker, son and Bourn, London.

Monteiro, C. A., Pfeiler, T. M., Patterson, M. D., \& Milburn, M. A. (2017). The Carnism Inventory: Measuring the Ideology of Eating Animals. Appetite.

Mundfrom, D. J., Shaw, D. G., \& Ke, T. L. (2005). Minimum Sample Size 
Recommendations for Conducting Factor Analyses. International Journal of Testing, 5(2), 159-168. https: / / doi.org/10.1207/ s15327574ijt0 5024

Nunnally, J. C. (1978). Psychometric theory (2nd ed.). New York, NY: McGraw-Hill.

Paolacci, G., \& Chandler, J. (2014). Inside the Turk: Understanding Mechanical Turk as a participant pool. Current Directions in Psychological Science, 23(3), 184-188.

Penner, L. A., Fritzsche, B. A., Craiger, J. P., \& Freifeld, T. R. (1995). Measuring the prosocial personality. Advances in Personality Assessment, 10, 147-163.

Piazza, J., \& Loughnan, S. (2016). When Meat Gets Personal, Animals' Minds Matter Less: Motivated Use of Intelligence Information in Judgments of Moral Standing. Social Psychological and Personality Science, 7(8), 867-874.

Piazza, J., Ruby, M. B., Loughnan, S., Luong, M., Kulik, J., Watkins, H. M., \& Seigerman, M. (2015). Rationalizing meat consumption. The 4Ns. Appetite, 91, 114-128.

Plous, S. (1993). Psychological mechanisms in the human use of animals. Journal of Social Issues, 49(1), 11-52.

Poteat, V. P., \& Mereish, E. H. (2012). Ideology, prejudice, and attitudes toward sexual minority social policies and organizations. Political Psychology, 33(2), 211-224.

Pratto, F., Sidanius, J., Stallworth, L. M., \& Malle, B. F. (1994). Social dominance orientation: A personality variable predicting social and political attitudes. Journal of Personality and Social Psychology, 67(4), 741.

Rand, D. G. (2012). The promise of Mechanical Turk: How online labor markets can help theorists run behavioral experiments. Journal of Theoretical Biology, 299, 172-179.

Rothgerber, H. (2013). Real men don't eat (vegetable) quiche: Masculinity and the justification of meat consumption. Psychology of Men E Masculinity, 14(4), 363.
Rozin, P., Hormes, J. M., Faith, M. S., \& Wansink, B. (2012). Is meat male? A quantitative multimethod framework to establish metaphoric relationships. Journal of Consumer Research, 39(3), 629643.

Ruby, M. B., \& Heine, S. J. (2011). Meat, morals, and masculinity. Appetite, 56(2), 447-450.

Ryder, R. D. (2006). Speciesism in the laboratory. In Defense of Animals: The Second Wave, 87-103.

Scott Long, J. (1997). Regression models for categorical and limited dependent variables. Advanced Quantitative Techniques in the Social Sciences, 7.

Shapiro, D. N., Chandler, J., \& Mueller, P. A. (2013). Using Mechanical Turk to study clinical populations. Clinical Psychological Science, 1, 213-220.

Shoukri, M. M., Asyali, M. H., \& Donner, A. (2004). Sample size requirements for the design of reliability study: review and new results. Statistical Methods in Medical Research, 13(4), 251-271.

Simoons, F. J. (1990). Food in China: a cultural and historical inquiry. CRC Press.

Singer, P. (1975). Animal Liberation. HarperCollins.

Singer, P. (1979). Practical Ethics. Cambridge University Press

Singer, P., \& Mason, J. (2007). The ethics of what we eat: Why our food choices matter. Rodale.

Soper, D.S. (2017). A-priori Sample Size Calculator for Multiple Regression [Software]. Available from http: / / www.danielsoper.com/statcalc

Stanovich, K. E., \& West, R. F. (1997). Reasoning independently of prior belief and individual differences in actively open-minded thinking. Journal of Educational Psychology, 89(2), 342.

Steiger, J. H. (2007). Understanding the limitations of global fit assessment in structural equation modeling. Personality and Individual differences, 42(5), 893-898.

Stern, C., West, T. V., Jost, J. T., \& Rule, N. O. (2013). The politics of gaydar: 
Ideological differences in the use of gendered cues in categorizing sexual orientation. Journal of Personality and Social Psychology, 104(3), 520.

Swim, J. K., Aikin, K. J., Hall, W. S., \& Hunter, B. A. (1995). Sexism and racism: Oldfashioned and modern prejudices. Journal of Personality and Social Psychology, 68(2), 199.

Taylor, N., \& Signal, T. D. (2005). Empathy and attitudes to animals. Anthrozoös, 18(1), 18-27.

Waytz, A., Gray, K., Epley, N., \& Wegner, D. M. (2010). Causes and consequences of mind perception. Trends in Cognitive Sciences, 14(8), 383-388.

Williams, B. (2009). The human prejudice. Peter Singer Under Fire: The Moral Iconoclast Faces His Critics, 3, 77.

Wuensch, K. L., Jenkins, K. W., \& Poteat, G. M. (2002). Misanthropy, idealism and attitudes towards animals. Anthrozoös, 15(2), 139-149.

Yuker H. E., Block J. R., \& Young J. H. The measurement of attitudes toward disabled persons. Albertson NY: Human Resources Center, 1970. 


\section{Table 1}

Factor loadings from the second EFA (Study 1)

\begin{tabular}{|c|c|c|c|}
\hline Item & Item Label & Factor 1 & Factor 2 \\
\hline $1^{*}$ & Humans have the right to use animals however they want to. & .742 & \\
\hline $2^{*}$ & $\begin{array}{l}\text { It is morally acceptable to keep animals in circuses for human } \\
\text { entertainment. }\end{array}$ & .701 & \\
\hline 3 & $\begin{array}{l}\text { It is morally acceptable to kill animals, because they are less } \\
\text { intelligent than humans. }\end{array}$ & 682 & \\
\hline $4^{*}$ & It is morally acceptable to hunt animals for sport. & .665 & \\
\hline $5^{*}$ & Morally, animals always count for less than humans. & 638 & \\
\hline $6^{*}$ & It is morally acceptable to do cosmetic research on animals. & 631 & \\
\hline $7^{*}$ & $\begin{array}{l}\text { Some beings are morally more important than others just because } \\
\text { they belong to a certain species. }\end{array}$ & 602 & \\
\hline 8 & A pig has a lower capacity to suffer than a human baby. & .598 & \\
\hline $9^{*}$ & $\begin{array}{l}\text { It is morally acceptable to perform medical experiments on animals } \\
\text { that we would not perform on any human. }\end{array}$ & .597 & \\
\hline 10 & A pig has a lower capacity to suffer than a dog. & .585 & \\
\hline 11 & $\begin{array}{l}\text { It is morally acceptable to kill animals even it is not necessary for } \\
\text { our own survival. }\end{array}$ & .582 & \\
\hline $12^{*}$ & $\begin{array}{l}\text { Basic rights that are enjoyed by humans - like protection from } \\
\text { harm - should also be granted to animals. }\end{array}$ & -.582 & \\
\hline 13 & $\begin{array}{l}\text { Reducing pain and suffering in animals is morally equally } \\
\text { important as reducing pain and suffering in humans. }\end{array}$ & -.577 & \\
\hline 14 & $\begin{array}{l}\text { It is morally acceptable to breed animals just to produce leather out } \\
\text { of their skin. }\end{array}$ & .560 & \\
\hline $15^{*}$ & It is morally acceptable to trade animals like possessions. & .545 & \\
\hline 16 & $\begin{array}{l}\text { If an elephant hurts itself in nature, it is morally acceptable not to } \\
\text { help even if it were morally required to help a human in the same } \\
\text { situation. }\end{array}$ & .532 & \\
\hline $17^{*}$ & $\begin{array}{l}\text { Chimpanzees should have basic legal rights such as a right to life } \\
\text { or a prohibition of torture. }\end{array}$ & -.527 & \\
\hline 18 & $\begin{array}{l}\text { It is morally acceptable to kill animals that destroy human } \\
\text { property, for example, rats, mice, or pigeons. }\end{array}$ & .502 & \\
\hline 19 & It is morally worse to kill any human than to kill a chimpanzee. & .485 & \\
\hline 20 & Factory farming of animals is morally wrong. & -.397 & \\
\hline 21 & Pigs should be taken care of by humans just like dogs are. & -.373 & \\
\hline 22 & $\begin{array}{l}\text { Faced with a decision of killing one human embryo or one pig, we } \\
\text { should always kill the pig. }\end{array}$ & .365 & \\
\hline $23+$ & It is morally wrong to eat fish. & & .820 \\
\hline $24+$ & It is morally wrong to consume milk and eggs. & & .743 \\
\hline $25+$ & $\begin{array}{l}\text { It is morally required to become vegetarian in an effort to save } \\
\text { animals. }\end{array}$ & & .648 \\
\hline $26+$ & $\begin{array}{l}\text { It is morally acceptable for cattle and pigs to be raised for human } \\
\text { consumption. }\end{array}$ & & -.529 \\
\hline $27+$ & It is morally acceptable to hunt wild animals for food. & & -.528 \\
\hline
\end{tabular}

Notes. * included in CFA's first factor, + included in CFA's second factor 


\section{Table 2}

Speciesism Scale

\begin{tabular}{|c|c|}
\hline Item & Item Label \\
\hline 1 & Morally, animals always count for less than humans. \\
\hline 2 & Humans have the right to use animals however they want to. \\
\hline 3 & It is morally acceptable to keep animals in circuses for human entertainment. \\
\hline 4 & It is morally acceptable to trade animals like possessions. \\
\hline 5 & $\begin{array}{l}\text { Chimpanzees should have basic legal rights such as a right to life or a prohibition of } \\
\text { torture. }(\mathrm{r})\end{array}$ \\
\hline 6 & $\begin{array}{l}\text { It is morally acceptable to perform medical experiments on animals that we would not } \\
\text { perform on any human. }\end{array}$ \\
\hline
\end{tabular}

Notes. Answers on a 7-point scale from "Strongly disagree" to "Strongly agree". (r) indicates reversed scoring.

\section{Table 3}

Correlations between speciesism and other constructs as well as partial correlations ( $p r)$ when controlled for SDO (Study 4)

\begin{tabular}{lll}
\hline Constructs & $\mathrm{r}$ & $\mathrm{pr}$ \\
\hline Social Dominance Orientation & $.42^{\cdots}$ & \\
Racism & $.32 \cdots$ & .01 \\
Sexism & $.41^{\cdots}$ & $.20^{\prime}$ \\
Homophobia & $.17^{\cdots}$ & .04 \\
Conservatism & $.25^{\cdots}$ & .07 \\
System Justification & $.25^{\cdots}$ & $.15^{+}$ \\
Right-Wing Authoritarianism & $.14^{-}$ & -.08 \\
Empathic Concern & $-.46^{\cdots}$ & $-.31^{\cdots}$ \\
Actively Open-Minded Thinking & -.17 & .05 \\
\hline
\end{tabular}

Notes. Degrees of freedom were 243. $+\mathrm{p}<.10 .{ }^{*} \mathrm{p}<.05 .{ }^{* *} \mathrm{p}<.01 .{ }^{* * *} \mathrm{p}<.001$. Bonferroni adjusted alpha level was .006. 


\section{Table 4}

Beliefs about intelligence and suffering capability (ratings on a scale from 0 to 100) and correlations of these beliefs with speciesism (Study 4)

\begin{tabular}{lllll}
\hline & \multicolumn{2}{c}{ Beliefs in $M(S D)$} & \multicolumn{2}{c}{ Correlation with speciesism } \\
\hline Species & Intelligence & $\begin{array}{l}\text { Suffering } \\
\text { capability }\end{array}$ & Intelligence & $\begin{array}{l}\text { Suffering } \\
\text { capability }\end{array}$ \\
\hline Humans & $87.79(12.88)$ & $96.88(6.82)$ & -.04 & -.15 \\
Animals & $39.71(19.71)$ & $84.20(20.39)$ & -.27 & $-.29 \cdots$ \\
Mentally severely disabled & $54.14(26.44)$ & $89.96(15.31)$ & 0.6 & -.10 \\
humans & $66.84(22.61)$ & $91.92(13.37)$ & -.20 & -.25 \\
Chimpanzees & $55.09(21.25)$ & $91.33(12.34)$ & -.18 & $-.28 \cdots$ \\
Dogs & $51.43(25.70)$ & $87.07(18.38)$ & -.23 & $-.29 \cdots$ \\
Pigs & & & & \\
\hline
\end{tabular}

Notes. $\cdot \mathrm{p}<.05 .{ }^{\prime} \mathrm{p}<.01 . \quad \cdots \mathrm{p}<.001$. 


\section{Table 5}

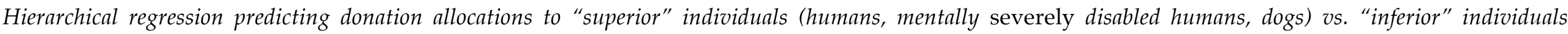
(animals, chimpanzees, pigs), displaying the standardized coefficients (beta) (Study 4)

\begin{tabular}{|c|c|c|c|c|c|c|c|c|c|c|c|c|}
\hline \multirow[b]{2}{*}{ Predictor measures } & \multicolumn{4}{|c|}{ Humans vs. Animals } & \multicolumn{4}{|c|}{ Mentally Severely Disabled Humans vs. Chimpanzees } & \multicolumn{4}{|c|}{ Dogs vs. pigs } \\
\hline & Step 1 & Step 2 & Step 3 & Step 4 & Step 1 & Step 2 & Step 3 & Step 4 & Step 1 & Step 2 & Step 3 & Step 4 \\
\hline$\Delta \mathrm{R}^{2}$ & .02 & .04 & .11 & .17 & .03 & .04 & .17 & .07 & .01 & .05 & .04 & .07 \\
\hline Gender & -.01 & -.03 & -.14 & $-.15^{+}$ & .06 & .02 & .16 & $.17^{+}$ & .05 & .03 & .03 & .01 \\
\hline Age & -.10 & -.13 & -.09 & -.03 & .12 & .13 & .08 & .04 & -.07 & -.09 & -.07 & -.01 \\
\hline Education & .03 & .03 & .03 & .08 & .12 & .12 & .12 & .09 & .02 & .03 & .00 & .04 \\
\hline Income & .05 & .06 & .04 & .00 & -.06 & -.08 & -.13 & -.09 & -.07 & -.07 & -.07 & -.10 \\
\hline SDO & & -.08 & .04 & .06 & & .02 & .03 & -.08 & & -.15 & -.13 & -.01 \\
\hline Empathic concern & & .07 & -.11 & -.06 & & .00 & .05 & .12 & & .14 & .06 & -.01 \\
\hline Perspective taking & & -.14 & .04 & -.01 & & .19 & $.21^{+}$ & .14 & & .12 & .15 & .22 \\
\hline Other-oriented & & -.08 & -.11 & -.13 & & .03 & .04 & .08 & & -.11 & -.13 & -.18 \\
\hline Mutual concern & & .23 & -.07 & $.21^{+}$ & & -.08 & -.14 & -.14 & & -.11 & -.06 & -.07 \\
\hline Ableism & & & & & & .12 & .04 & .05 & & & & \\
\hline Suffering "superior" & & & .05 & .04 & & & .18 & $.17^{+}$ & & & -.43 & -.43 \\
\hline Suffering "inferior" & & & .14 & .06 & & & -.21 & -.18 & & & .47 & .42 \\
\hline Intelligence "superior" & & & -.26 & -.21 & & & .29 & .25 & & & .02 & -.01 \\
\hline Intelligence "inferior" & & & .25 & .13 & & & -.27 & -.22 & & & .05 & .01 \\
\hline Speciesism & & & & $-.46 \cdots$ & & & & .30 & & & & -.27 \\
\hline
\end{tabular}

Notes. ${ }^{*} p<.10 . \cdot p<.05$. $" p<.01 . \cdots p<.001$. 
Table 6

Hierarchical logistic regression predicting whether participants chose the human or animal charity, displaying $\operatorname{Exp}(B)($ Study 5)

\begin{tabular}{lllll}
\hline Predictor measures & Step 1 & Step 2 & Step 3 & Step 4 \\
\hline $\mathrm{R}^{2}$ & .00 & .09 & .11 & .23 \\
\hline Gender & 1.04 & .85 & .99 & 1.23 \\
Age & 1.02 & 1.01 & 1.01 & 1.02 \\
SDO & & $.64^{+}$ & $.64^{+}$ & $.62^{+}$ \\
Empathic concern & & 1.58 & 1.69 & $1.97^{+}$ \\
Suffering humans & & 1.00 & 1.01 \\
Suffering chimpanzees & & & .996 & 1.00 \\
Intelligence humans & & & 1.02 & 1.00 \\
Intelligence chimpanzees & & & .98 & .99 \\
Speciesism & & & 3.43 \\
\hline
\end{tabular}

Notes. ${ }^{+} \mathrm{p}<.10 . \cdot \mathrm{p}<.05 .{ }^{\prime \prime} \mathrm{p}<.01 .{ }^{\prime \prime} \mathrm{p}<.001$.

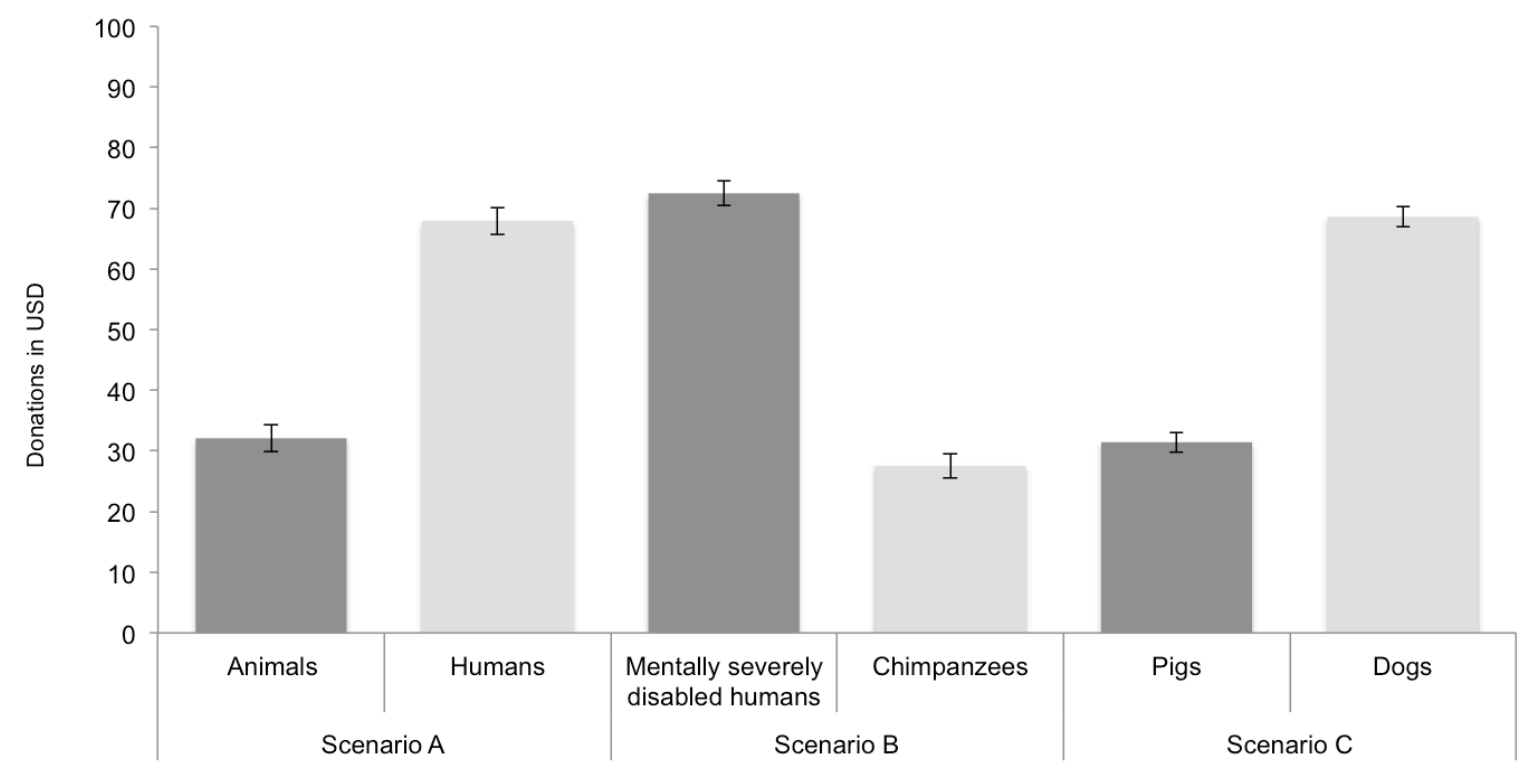

Figure 1. Average donation allocations to the charities (Study 4). In all three scenarios allocations significantly differed from an equal distribution of 50 donation points each. Error bars represent standard errors of the mean. 


\section{Appendix}

\section{Speciesism Scale}

1. Morally, animals always count for less than humans.

2. Humans have the right to use animals however they want to.

3. It is morally acceptable to keep animals in circuses for human entertainment.

4. It is morally acceptable to trade animals like possessions.

5. Chimpanzees should have basic legal rights such as a right to life or a prohibition of torture. $(\mathrm{r})$

6. It is morally acceptable to perform medical experiments on animals that we would not perform on any human.

Participants answer on 7-point scale from "Strongly disagree" to "Strongly agree". The fifth item (labelled with ' $\mathrm{r}$ ', indicates reversed scoring). After reverse-coding this item, scores should be averaged together to create an overall mean score of speciesism 